\title{
CHARACTERISATION OF HUMAN GINGIVAL NEURAL CREST-DERIVED STEM CELLS IN MONOLAYER AND NEUROSPHERE CULTURES
}

\author{
B.P. Fournier ${ }^{1 \S}$, L.S. Loison-Robert ${ }^{1 \S}$, F.C. Ferré ${ }^{1}$, G.R. Owen ${ }^{2}$, H. Larjava ${ }^{2}$ and L. Häkkinen²* \\ ${ }^{1}$ Cordeliers Research Center, Team “Oral Molecular Physiopathology”, INSERM UMR1138, \\ Paris Descartes and Paris Diderot University, Paris, France. \\ ${ }^{2}$ Department of Oral Biological and Medical Sciences, Faculty of Dentistry, University of British Columbia, \\ Vancouver, BC, Canada.
}

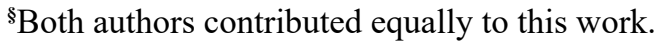

\begin{abstract}
Neural crest (NC)-derived stem cells (NCSC) have an exceptionally wide differentiation potential, but their use in regenerative therapy has been hampered by their scarcity in adult tissues and complex isolation protocols. Human oral mucosal gingiva may provide an attractive source of these cells as it contains NC-derived cells, the tissue is easily accessible and wound healing is fast and scarless with very little morbidity. To this end, we first investigated whether NC-derived cells are retained in adult gingiva by examining 8-months-old NC-reporter Wnt1Cre/R26RYFP mice. We then hypothesised that gingival cell NC-like phenotype can be further enhanced by floating neurosphere cultures generated from standard human gingival fibroblast (GF) and pooled CFU-F (GSC) cultures. Findings showed that NC-derived cells are retained in the gingival connective tissue of aged mice. Human GFs and GSCs expressed NC-related genes nestin, Snai1, Twist1, Pax3, Sox9 and FoxD3, and generated neurospheres. This was mediated via calcium- and connexin 43-dependent cell communication, which is similar to neurospheres formed by neural progenitors. Cells in the spheres showed significantly increased expression of NC-related genes, and down regulation of fibroblast-related type I collagen. Structurally, the neurospheres were polarised with nestin positive cells located on the outer layers underlined with an extracellular matrix rich in molecules typical to embryonic NC. Sphere-derived cells expressed significantly elevated levels of neural markers, and differentiated into Tau, neurofilament-M and GFAP-positive cells suggesting neural differentiation potential. Thus, human GF and GSC cultures may provide an efficient source of $\mathrm{NC}$-derived cells via enrichment by floating sphere cultures.
\end{abstract}

Keywords: Neural crest, stem cell, oral mucosa, gingiva, neurosphere, gene expression, differentiation, neural differentiation.

*Address for correspondence:

Dr. Lari Häkkinen,

University of British Columbia,

Faculty of Dentistry,

Department of Oral Biological and Medical Sciences,

2199 Wesbrook Mall,

Vancouver, BC,

V6T 1 Z3 Canada

Telephone number: +604-822-0096

Email: lhakkine@dentistry.ubc.ca
Introduction

Many of the oral tissues, including dental pulp, periodontal ligament, buccal mucosa and gingiva contain tissue specific mesenchymal progenitor cells that have self-renewal and multipotent differentiation capacity (Fournier et al., 2010; Fournier et al., 2013; Zhang et al., 2009). Potential use of these adult oral progenitor cells in cellular therapy has attracted considerable interest due to their easy access. Gingiva in particular, the part of oral mucosa that closely surrounds the teeth, is an attractive source of progenitor cells, as tissue biopsies for cell isolation are easy to collect without the need for tooth extraction. Furthermore, gingival tissue has a distinct capacity for fast and scarless wound healing following biopsy, and donors experience very little morbidity (Glim et al., 2013; Häkkinen et al., 2014). The therapeutic potential of gingival tissue has also been recognised in vivo (Häkkinen et al., 2014). For instance, different gingival tissue grafting procedures within oral cavity have been used in clinical practice for decades. In addition, gingival grafts have been successful in extraoral sites. For example, full-thickness autologous grafts from palatal gingival mucosa have been used for eyelid reconstruction with good clinical outcomes (Siegel, 1985; Weinberg et al., 2007), and in animal models, gingival fibroblasts have been successful in tracheal or vascular repair (Durand et al., 2012; Kobayashi et al., 2007). In spite of recent progress in the field, identification and characterisation of tissue specific progenitor cells and their relationship with fibroblasts in gingiva remains elusive. Therefore, better understanding of the properties of gingival cells would be needed to further enhance their prospect in cellular therapies (Häkkinen et al., 2014).

Certain tissues in the body, including most of the oral and craniofacial tissues, originate from the neural crest (NC) migrating cells during development (Barbu et al., 1986; Chai et al., 2000; Gammill and Bronner-Fraser, 2003; Ibarretxe et al., 2012; Kaltschmidt et al., 2012; La Noce et al., 2014; Le Douarin et al., 2008; Le Douarin, 2012; Le Lièvre and Le Douarin, 1975). As a result, daughter cells of these NC cells (post-migratory NC cells) are found in the adult tissues. These include fibroblasts and various tissue-specific progenitor cell populations (Le Douarin et al., 2008; Yoshida et al., 2008). The NC origin has been particularly associated with distinct phenotype of tissuespecific progenitor cells, which include so-called skinderived precursor cells (SKP) present in facial skin, and post-migratory NC stem cells (pNCSCs) (Fernandes et al., 2008). For instance, these cells have exceptionally wide 
differentiation capacity into various ectomesenchymal cell types, i.e. mesenchymal lineages such as fibroblasts, myofibroblasts, osteoblasts, chondroblasts, myoblasts and adipocytes, and to neural lineages that include neurons and glial cells (Dupin et al., 2007; Kaltschmidt et al., 2012). Thus, when efficiently isolated from tissue, the NC-derived cells may provide remarkable versatility for tissue regenerative modalities. Best characterised tissue niches for pNCSCs include the bone marrow and hair follicles in skin (Dupin and Sommer, 2012; Hunt et al., 2009; Kaltschmidt et al., 2012; Sieber-Blum et al., 2004). They have also been found in tooth-related tissues in the oral cavity, such as dental pulp (Arthur et al., 2008; Chai et al., 2000; Stevens et al., 2008) and periodontal ligament (Kawanabe et al., 2010; Widera et al., 2007). However, cells with similar properties can also be isolated from skin areas lacking hair follicles, such as neonatal foreskin (Toma et al., 2005), or oral locations not directly associated with teeth, namely buccal (cheek) mucosa and lamina propria of hard palate (Dong et al., 2010; Kaltschmidt et al., 2012; Weber et al., 2015; Widera et al., 2009). While NC cells are abundantly found in the dental pulp (Arthur et al., 2008; Chai et al., 2000; Stevens et al., 2008), they appear to be rare in most other adult tissues (Nagoshi et al., 2008), and their abundance further decreases during aging (Hunt et al., 2009). Lineage-tracing of NC-derived cells in juvenile transgenic Wnt1-reporter mice gingiva has indicated that majority of connective tissue cells also in gingiva are of NC origin (Xu et al., 2013), but it is unclear if these cells are retained during aging in vivo. Additionally, in standard cultures of human gingival connective tissue cells, a large proportion of cells have been reported to express neural and NC-related genes, including nestin and p75 low-affinity neurotrophin receptor (p75NTR), and possess both mesodermal and neurogenic differentiation capacity when appropriately stimulated (Ganz et al., 2014; Marynka-Kalmani et al., 2010). Thus, gingival connective tissue may contain NC-derived cells, but their NC-related properties have not been characterised in detail.

A defining feature of NC-related progenitor cells is that, contrary to their mesoderm-derived counterparts, they constitutively express neural-progenitor markers, such as nestin, and possess high neurogenic differentiation potential when appropriately stimulated (Ibarretxe et al., 2012). Recent studies have shown that floating neurosphere cultures, originally developed to isolate and expand neural stem cells, may be effective in isolating and selecting these progenitors from various tissues, including skin, periodontal ligament and dental pulp (Abe et al., 2012; Techawattanawisal et al., 2007; Toma et al., 2001). In this protocol, cells are enzymatically released from the tissue and then cultured as floating spheres in serum-free medium supplemented with EGF and FGF2 (Pastrana et al., 2011; Toma et al., 2001). This is in contrast with traditional fibroblast or mesenchymal stem cell cultures where cells are cultured in serum-containing media as plastic adherent cells (Fournier et al., 2013; Häkkinen et al., 2014). Although valuable in selecting NC-derived progenitors, floating sphere cultures established from cells that are directly released from tissue by enzymatic digestion is impractical and inefficient in large-scale applications.
In skin, frequency of NC-related progenitors is also strongly reduced during aging limiting the availability of appropriate donor material (Gago et al., 2009; Hunt et al., 2009). Therefore, in the present study, we wanted to find out whether NC-derived cells are retained in adult gingiva. To this end, we studied the presence of these cells in gingiva in aged ( 8 months old) mice. In addition, we tested for the first time whether human gingiva contains $\mathrm{NC}$-like cells that can be propagated from standard plastic adherent cell cultures to form neurospheres. To this end, we assessed the NC-like characteristics of standard cultures of human gingival fibroblasts (GFs) and pooled CFU-F cultures (GSC) generated from the GF cultures. We have previously shown that such GSC cultures contain progenitor cells with multipotent differentiation potential (Fournier et al., 2013). We then evaluated whether these cultures can be used to generate floating spheres, if they share characteristics with classical neurospheres that have been used to enrich and test NC-like stem cell potential, and if neurosphere generation can be used to enhance the NC-like phenotype of the gingival cells. Finally, phenotype of the human gingival sphere-derived cells was analysed and compared to their plastic adherent counterparts, and their neural differentiation potential tested.

\section{Materials and Methods}

\section{Detection of post-migratory neural crest-derived cells in mouse tissues}

Marginal and attached gingiva from maxilla and abdominal skin biopsies were collected from two 8-month-old male Wnt1-Cre/R26RYFP mice that were engineered to express yellow fluorescent protein (YFP) under the control of Wnt1 promoter during embryonic development. In these adult mice, cells that originate from the NC during development are permanently labelled with YFP representing postmigratory NC cells (a generous gift from Dr. Fabio Rossi, University of British Columbia, Vancouver, BC, Canada) (Lemos et al., 2012). Tissue samples were immediately fixed in $4 \%$ paraformaldehyde at room temperature for $2 \mathrm{~h}$ and then placed in O.C.T. compound (Tissue-Tek, Torrence, CA, USA) and snap-frozen in liquid nitrogen. Frozen section $(5 \mu \mathrm{m})$ were cut and stored at $-86^{\circ} \mathrm{C}$. Tissue sections were observed using a Leica SP5X White Light Laser Confocal Microscope DMI 5000 equipped with an YFP filter (excitation wavelength 490-510 nm; Leica Microsystems Inc., Concord, ON, Canada). Procedures were reviewed and approved by the University of British Columbia Animal Ethics Committee.

\section{Cell culture}

Human gingival fibroblast (GF) cultures were established from biopsies of clinically healthy attached gingiva from three healthy female donors (average age 13 years) undergoing gingival surgery for tooth exposure for orthodontic treatment. All patients gave their informed consent according to the Helsinki Declaration (1975). The procedures were reviewed and approved by the University of British Columbia Clinical Research Ethics Board. GF cultures were established either as explant cultures or by 
Table 1. Composition of culture media used for floating sphere formation.

\begin{tabular}{|c|c|c|c|c|c|c|c|c|}
\hline \multirow[t]{2}{*}{ Medium } & \multicolumn{8}{|c|}{ Composition } \\
\hline & Basal Medium & $\begin{array}{c}\text { Glutamine }^{1} \\
(\mathrm{mM})\end{array}$ & $\begin{array}{c}\mathrm{EGF}^{1} \\
(\mathrm{ng} / \mathrm{mL})\end{array}$ & $\begin{array}{c}\text { FGF }^{1} \\
(\mathrm{ng} / \mathrm{mL})\end{array}$ & $\begin{array}{l}\text { Insulin }^{1} \\
(\mu \mathrm{g} / \mathrm{mL})\end{array}$ & $\begin{array}{c}\text { Transferrin }^{1} \\
(\mu \mathrm{g} / \mathrm{mL})\end{array}$ & $\begin{array}{l}\mathrm{N}^{2} \\
(\%)\end{array}$ & $\begin{array}{l}\mathrm{B} 27^{2} \\
(\%)\end{array}$ \\
\hline NS1 (1) & Neurobasal medium $^{2}$ & 2 & & 20 & & & 2 & \\
\hline NS2 (2) & $\mathrm{DMEM} / \mathrm{F} 12^{1}$ & & 20 & 20 & & & & \\
\hline NS3 (3) & $\mathrm{DMEM} / \mathrm{F} 12^{1}$ & 2 & 20 & 20 & 25 & 100 & & \\
\hline NS4 (4) & $\mathrm{DMEM} / \mathrm{F} 12^{1}$ & & 20 & 40 & & & & 2 \\
\hline NP1 & \multicolumn{8}{|c|}{ NPMM $^{\mathrm{TM}}$ (Serum-free Neural Progenitor Maintenance Medium) ${ }^{3}$} \\
\hline NP2 & \multicolumn{8}{|c|}{ NPDM $^{\mathrm{TM}}$ (Neural Progenitor Differentiation Medium BulletKit) ${ }^{3}$} \\
\hline
\end{tabular}

releasing the cells from the biopsies by enzyme treatment (enzymatic method). In the explant method, biopsies were minced with a sterile scalpel and then placed in a culture plate. For the enzymatic method, the biopsies were digested with collagenase II (Worthington) at $37{ }^{\circ} \mathrm{C}$ for $2 \mathrm{~h}$. The released cells were collected by centrifugation and washed before seeding. The cells were routinely maintained in the classical low glucose DMEM containing $10 \%$ heat-inactivated foetal bovine serum (FBS), $100 \mathrm{U} /$ $\mathrm{mL}$ of penicillin $\mathrm{G}, 100 \mu \mathrm{g} / \mathrm{mL}$ streptomycin sulphate and $0.025 \mathrm{mg} / \mathrm{mL}$ amphotericin B mixture (CM; Life Technologies Corporation, Burlington, ON, Canada) and $50 \mu \mathrm{g} / \mathrm{mL}$ ascorbic acid phosphate (Wako Chemicals, Richmond, VA, USA) to promote cell growth (Jung et al., 2010; Kuznetsov et al., 1997). To generate CFU-F enriched cultures (GSCs, gingival stem cells), single-cell suspensions were seeded at low density $\left(<100\right.$ cells $\left./ \mathrm{cm}^{2}\right)$ on $10 \mathrm{~cm}$ Petri dishes and cultured as above until colonies appeared (Fournier et al., 2010; Zhang et al., 2009). All the colonies within each plate were then trypsinised, pooled and further expanded in culture as described above. A total of three GSC cultures were generated and used for the study, each of them having its parental fibroblast culture (GF) counterpart. Cells at passage 2-5 were used for the experiments.

\section{Floating sphere cultures}

To investigate the capacity of the cells to generate neurosphere-like structures, monolayer cultures were trypsinised, collected by centrifugation, and 25,000 cells $/ \mathrm{mL}$ were seeded on $6 \mathrm{~cm}$ non-tissue culture-treated dishes. First, six different culture media previously shown to support neurosphere formation (Table 1) were tested for their ability to generate floating spheres using GFs. Typically, the floating spheres were formed between the second and third day after seeding, and the sphere formation efficiency was scored at day five by a single examiner. The score (0-4) was based on the number and size of the spheres that formed ( 0 : no spheres; 1 : few small spheres; 2: some, mostly small spheres; 3: numerous, mostly small spheres; 4: numerous, very large spheres). The best medium (NS4; Table 1) was then used for more detailed characterisation of the floating spheres (see below). To assess sphere-forming efficiency in more detail, in a set of experiments, cells were seeded in NS4 medium on $6 \mathrm{~cm}$ non-tissue culture-treated dishes, and number of spheres formed after day five was calculated in five parallel phase contrast microscope fields per well using a $\times 4$ objective. For a set of experiments assessing importance of calcium $\left(\mathrm{Ca}^{2+}\right)$-dependent cell-cell contacts on sphere formation, the culture medium was depleted of $\mathrm{Ca}^{2+}$ using a chelator (Chelex ${ }^{\circledR}$ 100; Bio-Rad Laboratories, Mississauga, ON, Canada) as previously described (Price et al., 1983; Swierenga and Auersperg, 1982). The floating spheres used for these experiments were collected at day five.

\section{Neural differentiation assay}

Neural differentiation was carried out in DMEM containing $10 \%$ FBS and retinoic acid $\left(10^{-7} \mathrm{M}\right.$; Sigma-Aldrich; NeuM1) for $10 \mathrm{~d}$ or in DMEM/F12 supplemented with $1 \% \mathrm{~N} 2$ culture supplement and FGF2 (4 ng/mL; Gibco/ Life Technologies, Grand Island, NY, USA; NeuM2) for 3 weeks. Differentiation was assessed by immunostaining and qRT-PCR (see below).

\section{Analysis of mRNA expression by qRT-PCR and RT- PCR}

Total RNA was extracted from cultured cells using NucleoSpin ${ }^{8}$ RNA II kit and treated with rDNase (Macherey-Nagel, Duren, Germany) according to the manufacturer's protocol. Total RNA concentration and purity was measured by spectrophotometry (Nanodrop, Thermo Scientific, Wilmington, MA, USA) and samples with OD260/280 ratio above 1.8 were used for the study. cDNA was synthesised using iScript ${ }^{\mathrm{TM}}$ Select cDNA Synthesis Kit (Bio-Rad Laboratories) according to the manufacturer's instructions. All primers were designed on the boundaries of exons when possible, and analysed by BLASTn software (Web ref. 1) for specificity. The primers were designed to yield a target sequence that was $75-250$ base pairs long with a GC content between 40$60 \%$. RNA folding was tested using the RNAfold tool (Web ref. 2) to avoid secondary structures when possible. Efficiency of target amplification was set to 90-105\% based on optimisation using a dilution series of cDNA for each primer while standard curves were made. For the qRT-PCR reactions, diluted RT products were mixed with $7.5 \mu \mathrm{L}$ of $2 \mathrm{X}$ Kapa SYBR Fast qPCR (Kapa Biosystems, Wilmington, MA, USA) mix and 5 pmol primers, for a final volume of $15 \mu \mathrm{L}$. Real-time PCR amplification was 
Table 2. PCR primer sequences used for the study.

\begin{tabular}{|c|c|c|c|}
\hline Genes & Primers sequences $\left(5^{\prime}>3^{\prime}\right)$ & Size (bp) & Accession number \\
\hline B3-Tubulin & $\begin{array}{l}\text { F: TCTCACAAGTACGTGCCTCG } \\
\text { R: CAGGCAGTCGCAGTTTTCAC } \\
\end{array}$ & 225 & \begin{tabular}{|l|} 
NM_001197181.1 \\
NM_006086.3
\end{tabular} \\
\hline COL1A1 & $\begin{array}{l}\text { F: AACCAAGGCTGCAACCTGGA } \\
\text { R: GGCTGAGTAGGGTACACGCAGG }\end{array}$ & 80 & NM_000088.3 \\
\hline Connexin 43 & $\begin{array}{l}\text { F: AGCAGTCTGCCTTTCGTTGTA } \\
\text { R: GATTGGGAAAGACTTGTCATAGCAG }\end{array}$ & 73 & NM_000165.4 \\
\hline FOXD3 & \begin{tabular}{|l|} 
F : AGTGAAGCCGCCTTACTCGTACAT \\
R : AGGAAGCTGCCGTTGTCGAACAT \\
\end{tabular} & 265 & NM_012183.2 \\
\hline$G A P D H$ & $\begin{array}{l}\text { F: CTTTGTCAAGCTCATTTCCTGGTA } \\
\text { R: GGCCATGAGGTCCACCA } \\
\end{array}$ & 70 & NM_002046 \\
\hline$M A P 2$ & $\begin{array}{l}\text { F: CCTGCCCTAGCACGACTAAA } \\
\text { R: TGGTTACTCCGTCCTTGTTCC } \\
\end{array}$ & 120 & NM_001039538.1| \\
\hline Nestin & $\begin{array}{l}\text { F: CAGCGTTGGAACAGAGGTTGG } \\
\text { R: GGCTGGCACAGGTGTCTCAAG }\end{array}$ & 392 & NM_006617.1 \\
\hline$P A X 3$ & \begin{tabular}{|l|} 
F: TGTTCAGCTGGGAAATCCGAGA \\
R: AGCTGTTCTGCTGTGAAGGTGGTT \\
\end{tabular} & 309 & NM_181457.3 \\
\hline P75NTR & $\begin{array}{l}\text { F: TGGCCTACATAGCCTTCAAGA } \\
\text { R: GAGATGCCACTGTCGCTGT } \\
\end{array}$ & 124 & NM_002507.3| \\
\hline$S D H A$ & $\begin{array}{l}\text { F: AGCAAGCTCTATGGAGACCT } \\
\text { R: TAATCGTACTCATCAATCCG } \\
\end{array}$ & 199 & NM_004168.3 \\
\hline SNAII & $\begin{array}{l}\text { F: TCGGAAGCCTAACTACAGCGA } \\
\text { R: AGATGAGCATTGGCAGCGAG } \\
\end{array}$ & 140 & NM_005985.3 \\
\hline SOXO & $\begin{array}{l}\text { F: CTGTAGGCGATCTGTTGGGG } \\
\text { R: AGCGAACGCACATCAAGAC } \\
\end{array}$ & 85 & NM_000346.3 \\
\hline$S 100 B$ & \begin{tabular}{|l|} 
F: GGGAGACAAGCACAAGCTGA \\
R: CCTCCTGCTCTTTGATTTCCTCTA \\
\end{tabular} & 93 & NM_006272.2 \\
\hline Tenascin-C & $\begin{array}{l}\text { F: CAACCTGATGGGGAGATATGGGGA } \\
\text { R: GAGTGTTCGTGGCCCTTCCAG } \\
\end{array}$ & 77 & XM_005251975.2 \\
\hline TWIST1 & $\begin{array}{l}\text { F: TGCAGCTATGTGGCTCACGA } \\
\text { R: CCCACGCCCTGTTTCTTTGA }\end{array}$ & 266 & NM_000474.3 \\
\hline$U B C$ & $\begin{array}{l}\text { F: GTGGCACAGCTAGTTCCGT } \\
\text { R: CTTCACGAAGATCTGCATTGTCA }\end{array}$ & 96 & NM_021009.6 \\
\hline
\end{tabular}

performed on the CFX96 System (Bio-Rad Laboratories) using the following program: one cycle at $94^{\circ} \mathrm{C}$ for $3 \mathrm{~min}$, 35 cycles at $95^{\circ} \mathrm{C}$ for $5 \mathrm{~s}$, gene-specific annealing for $20 \mathrm{~s}$, and reaction completion with reading plate and a melt curve analysis from $65^{\circ} \mathrm{C}$ to $95^{\circ} \mathrm{C}, 5 \mathrm{~s}$ for each $0.5^{\circ} \mathrm{C}$. Amplification reactions were conducted for target genes with $\beta$-actin (BACT), succinate dehydrogenase complex subunit A flavoprotein (SDHA) and ubiquitin C (UBC) as reference genes. For a given qRT-PCR experiment, at least two reference genes were chosen based on the Bio-Rad CFX manager software. Non-transcribed RNA samples and a water control were used as negative controls. The PCR reactions were performed in triplicate for each sample. Gene expression analysis was performed using three parallel cell lines. The data was analysed based on the comparative $2 \Delta \Delta \mathrm{Ct}$ method (CFX Manager Software Version 2.1, Bio-Rad Laboratories). For primer sequences, see Table 2. In a set of experiments, the PCR products were also run on agarose gels $(1.5 \%)$ to confirm the correct amplicon size.

\section{Immunostaining}

Immunostainings were performed using two monoclonal anti-nestin antibodies (clone 10C2, EMD Millipore/ Chemicon, Billerica, MA, USA; MAB1259, R\&D Systems, Minneapolis, MN, USA), polyclonal (F3648,
Sigma-Aldrich) and monoclonal (HFN 7.1, Developmental Studies Hybridoma Bank, Iowa City, IA, USA) antifibronectin antibodies, and two monoclonal anti- $\beta 3$-tubulin antibodies (MAB1195, R\&D Systems; E7, Developmental Studies Hybridoma Bank). Both nestin, fibronectin and $\beta 3$-tubulin antibodies gave identical results, respectively (data not shown). Immunostainings were also performed using anti-Tau protein (EMD Millipore/Chemicon), anti-neurofilament-M (RT97, Developmental Studies Hybridoma Bank), anti-tenascin-C (GeneTex Inc., Irvine, CA, USA), anti-connexin 43 (Sigma-Aldrich), anti-collagen I (ab292, Abcam), anti-collagen IV (Vector Laboratories, Burlington, ON, Canada), anti-Ki67 (ab15580, Abcam), polyclonal anti-pan-laminin (Chemicon), and monoclonal anti-GFAP (ab4648, Abcam) antibodies. Actin filaments were stained using fluorochrome-coupled phalloidin (Life Technologies Corporation). Secondary antibodies were Alexa Fluor 488-conjugated goat anti-rabbit, Alexa Fluor 594-conjugated goat anti-mouse, Alexa Fluor 546-conjugated goat anti-mouse and Alexa Fluor 488-conjugated goat anti-mouse (Life Technologies Corporation).

For immunohistochemical analysis, monolayer and floating sphere cultures were fixed using phosphate buffered saline (PBS; $\mathrm{pH} 7.4$ ) containing $4 \%$ paraformaldehyde $/ 5 \%$ sucrose for $20 \mathrm{~min}$. For detection of intracellular molecules, 
cells were permeabilised using $0.5 \%$ Triton X-100. To block background staining, cells were treated with PBS containing $3 \% \mathrm{BSA} / 1 \%$ glycine at room temperature for $30 \mathrm{~min}$. Samples were then incubated with the primary antibody at $4{ }^{\circ} \mathrm{C}$ overnight or at room temperature for $2 \mathrm{~h}$. For double immunostaining, primary antibodies were incubated as above. Samples were then incubated with the appropriate secondary antibodies at room temperature for $1 \mathrm{~h}$. Cell nuclei were stained using DAPI (Life Technologies Corporation), followed by mounting of the samples using Immu-Mount solution (Thermo Scientific). To assess cell viability, cells were cultured in the presence of CellTrace Calcein Red-Orange AM (Life Technologies Corporation) as indicated by the supplier. Samples were observed and digital images recorded using Leica SP5X White Light Laser Confocal Microscope DMI 5000 (Leica Microsystems Inc., Concord, ON, Canada).

In a set of samples, cells were incubated with primary antibodies against Tau protein and neurofilament-M as above, followed by incubation with species-specific biotinylated secondary antibodies (Vectastain ABC kit; Vector Laboratories). Colour development was performed by using Vector VIP substrate (Vector Laboratories). Samples were counterstained using haematoxylin, mounted and observed with Nikon TS100 bright-field microscope (Nikon Canada, Mississauga, ON, Canada), and images captured using a Nikon Coolpix 995 digital camera (Nikon Canada). Control stainings were performed omitting the primary antibody, and gave negligible staining (data not shown).

For quantification of proportion of immunopositive cells in the cultures, at least five randomly selected microscopic fields using a $\times 20$ objective were counted by a single examiner. The results are presented as the total number of positive cells relative to total number of DAPI or haematoxylin stained cells in each sample.

\section{Scanning electron microscopy}

Floating spheres generated by the cells were collected using custom-made filter paper cones, fixed with $4 \%$ paraformaldehyde $/ 5 \%$ sucrose solution in PIPES for $10 \mathrm{~min}$, rinsed in PIPES and incubated in $2.5 \%$ glutaraldehyde in PIPES for $5 \mathrm{~min}$. After rinsing, spheres were incubated with $0.5 \%$ osmium tetroxide for $60 \mathrm{~min}$ followed by dehydration in specific grade alcohol, critical point drying and attached on sample holders using silver paint (Canemco-Marivac, St. Laurent, QC, Canada). The samples were examined using Helios NanoLab 650 Dual Beam Scanning Electron Microscope (FEI, Hillsboro, OR, USA).

\section{siRNA transfection}

siRNA transfection was carried out using Lipofectamine RNAiMax (Life Technologies Corporation). To this end, $22 \mu \mathrm{L}$ of Lipofectamine RNAiMax and $150 \mathrm{pmol}$ of connexin 43 siRNA(UUUUGCAAGUGUAAACAGC[dT] $[\mathrm{dT}]$ and AAUGAAAAGUACUGACAGC $[\mathrm{dT}][\mathrm{dT}])$ or control siRNA (ACUUCGACACAUCGACUGC[dT] [dT]) was mixed with $2.4 \mathrm{~mL}$ of Opti-MEM medium (Life Technologies Corporation) and incubated at room temperature for $5 \mathrm{~min}$. The mixtures of transfection reagent and individual siRNA were combined and incubated for complex formation at room temperature for $20 \mathrm{~min}$, diluted with Opti-MEM to final concentration of $30 \mathrm{nM}$, and added to the cells. After $5 \mathrm{~h}$ incubation in the cell culture incubator, the transfection medium was replaced with growth medium without antibiotics, and cells were cultured overnight before using for the experiments.

\section{Statistical analysis}

Statistical analysis was performed using Student's $t$-test, Wilcoxon test and one-way ANOVA (Kruskal-Wallis) with Bonferroni correction for multiple comparisons, and was carried out using Prism GraphPad 5 software (GraphPad Software Inc, La Jolla, CA, USA). Results are presented as mean \pm standard error of mean (SEM) from minimum of three biological replicates.

\section{Results}

\section{Gingival fibroblasts derive from neural crest}

In general, most of the oral and certain facial structures derive from the NC (Widera et al., 2012). However, whether the cells originating from the $\mathrm{NC}$ are retained in older adult animals is not known. Therefore, to assess the presence of NC-derived cells in mature adult gingiva in vivo, we analysed 8-months-old Wnt1-CRE/R26RYFP mice. In these mice, cells that express NC-specific Wnt1 during embryogenesis are induced to express the fluorescent YFP. Subsequently, all daughter cells also express this marker throughout the life of the animal representing postmigratory NC-derived cells (Lemos et al., 2012). Gingival tissue isolated from these mice showed typical gingival architecture with relatively thick keratinised epithelium and defined interdigitating epithelial/connective tissue interphase (Fig. 1a). Abdominal skin (derived from embryonic mesoderm), in contrast, showed typical mouse skin structure with thin keratinised epithelium and hair follicles (Fig. 1d). Gingival epithelium or endothelial cells of the blood vessels did not express YFP, but it was strongly expressed in most of the stromal cells in the connective tissue, including spindle-shaped fibroblast-like cells, and in cells around blood vessels (Fig. $1 \mathbf{b}$ and $\mathbf{c}$ ). In the abdominal skin specimens, there was no YFP signal in any of the cells of the epidermis or the dermis as expected (Fig. 1e and f), except that some cells in hair follicles showed weak staining (not shown) as also previously described (Jinno et al., 2010). Thus, NC-derived cells are also retained in gingival connective tissue of old animals.

To assess the putative NC origin of fibroblasts in human gingiva, we studied expression of a set of genes (Snai1, Twist1, Pax3, Sox9, nestin and FOXD3) typically highly expressed by NC-derived cells (Crane and Trainor, 2006; Teng and Labosky, 2006), in cultured human gingival cells. To this end, we established GF cultures from tissue biopsies of healthy human attached gingiva from three different donors. From these cultures, we also generated cell subpopulations by CFU-F technique (termed GSC). Results from RT-PCR showed that all GF and GSC lines expressed Snai1, Twist1, Sox9, nestin, FoxD3 and Pax3 (Fig. 1g and h). Assessment by qRT-PCR, showed that 

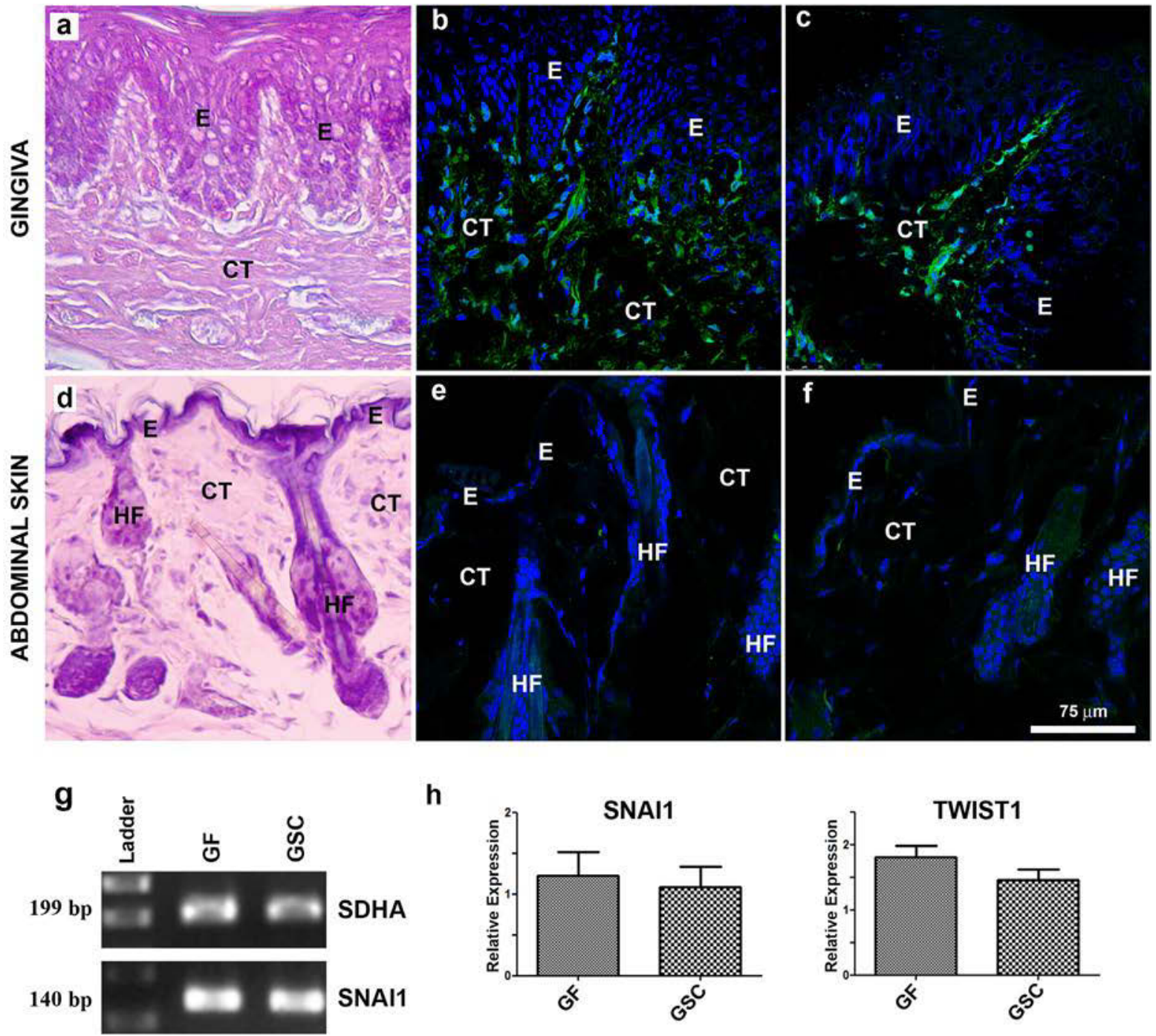

h
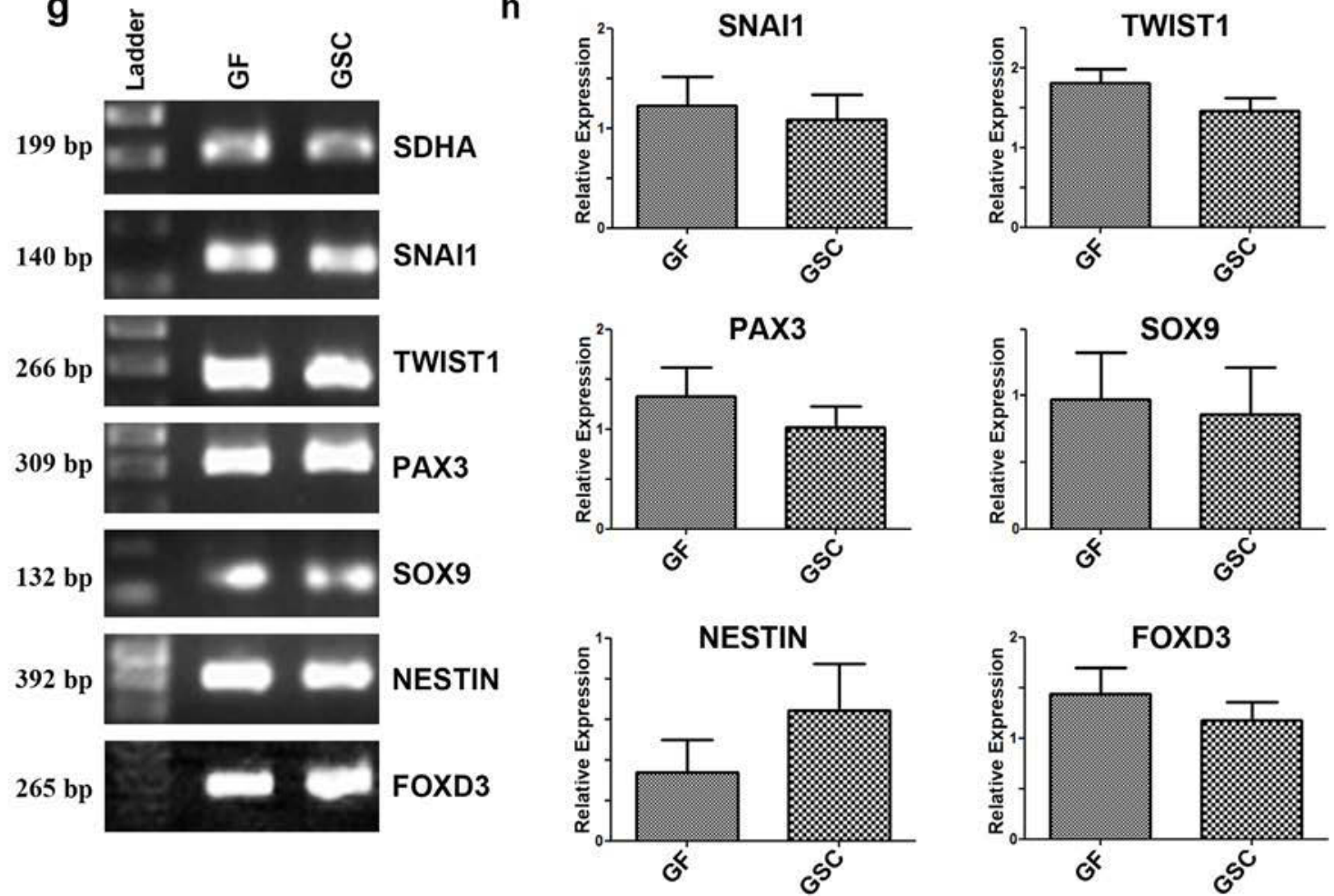

Fig. 1. Gingival cells derive from migratory neural crest cells and express neural crest-related genes. Representative tissue sections from 8-months-old Wnt1-CRE/R26RYFP transgenic mouse gingiva (a-c) and abdominal skin (d-f). Haematoxylin and eosin stained sections of gingiva (a) and abdominal skin (d). YFP-positive cells that derive from neural crest (NC) are abundantly present in gingival connective tissue (b and c), while no YFP-positive cells can be noted in the abdominal skin connective tissue (e and f). In gingiva, YFP-positive cells were enriched in connective tissue cells residing in the connective tissue papilla area between the epithelial rete ridges (c). E: epithelium; HF: hair follicle; CT: connective tissue. (g) Representative results from agarose gel electrophoresis analysis of expression of NCrelated SNAI1, TWIST1, PAX3, SOX9, Nestin and Foxd3 mRNA determined by RT-PCR in human gingival fibroblast (GF) and gingival stem cell (GSC) cultures. Both cultures expressed all of the NC-related genes. SDHA was used as a reference gene. (h) Quantification of relative mRNA expression by qRT-PCR. No statistically significant differences were noted in the expression level of the NC-related genes in GF and GSC cultures. 
a
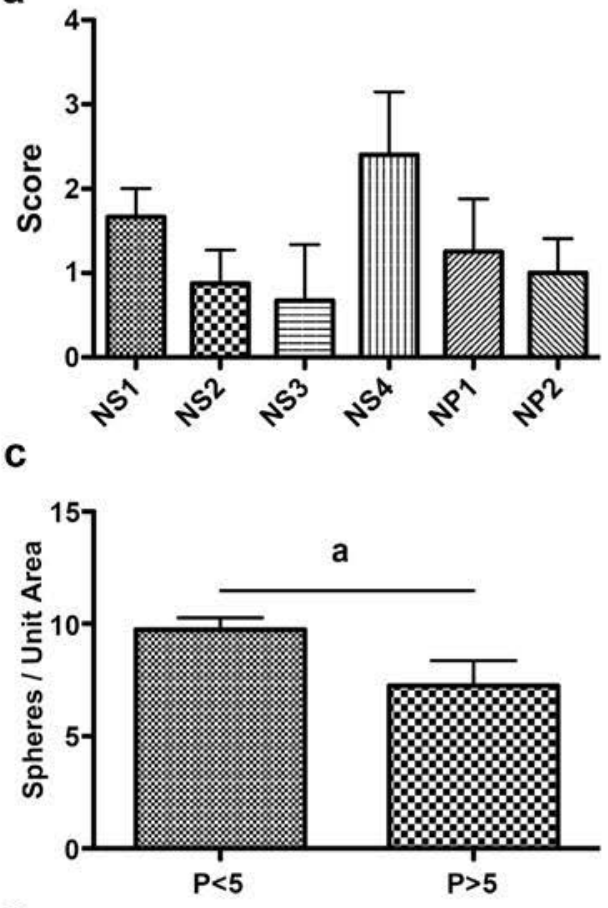

e

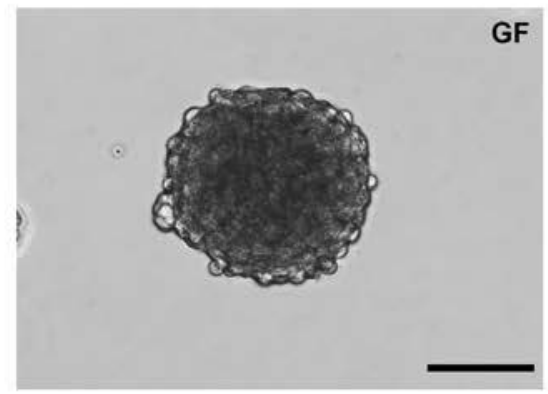

g

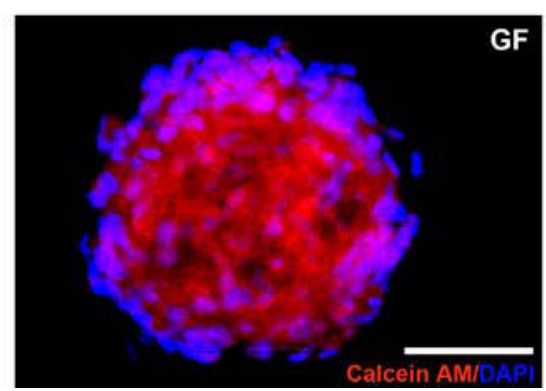

b
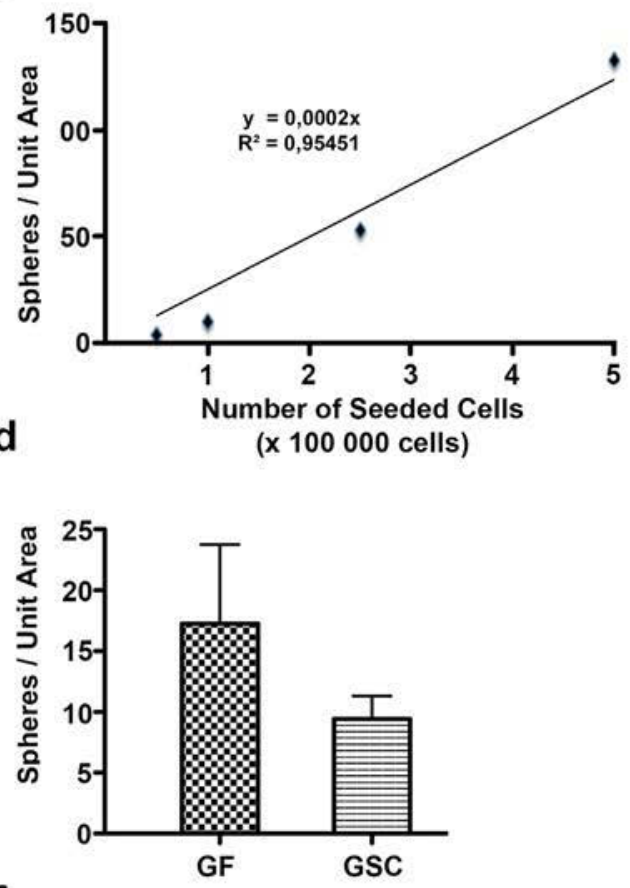

f

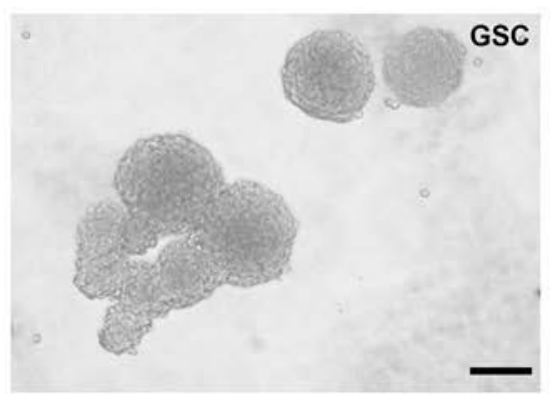

h

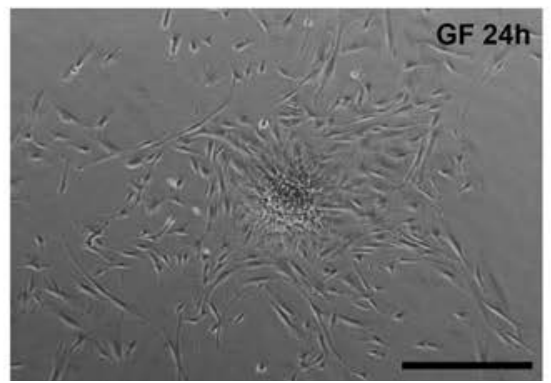

Fig. 2. Formation of neurospheres by cultured gingival cells. (a) Different culture media were assessed for their potential to promote neurosphere formation in cultured gingival fibroblasts (GFs) after $5 \mathrm{~d}$. A score (0-4) was given based on the neurosphere-like morphology and number of neurospheres that were formed. NS4 medium was most conducive for sphere formation, although the differences did not reach statistical significance. (b) Increasing concentrations of GFs were cultured as neurospheres in NS4 medium as above and the number of neurospheres that formed per unit area was counted. The number of neurospheres increased proportionally to the number of cells seeded. (c) Increasing passage of GFs from $<$ P5 to $>$ P5 reduced neurosphere formation significantly ( $a=p<0.05$, Student's $t$-test). (d) When GFs and CFU-enriched gingival fibroblasts (GSC) were compared (initial seeding density of 250,000 cells) for their capacity to form neurospheres, no statistically significant differences were noted. (e and $\mathbf{f})$ Phase-contrast images of neurospheres formed by GF (e) and GSC (f) cultures show similar sphere morphology in both cultures $5 \mathrm{~d}$ post-seeding. (g and $\mathbf{h})$ Viability of GFs in the neurospheres formed $5 \mathrm{~d}$ post-seeding. NS4 medium was tested using Calcein AM dye assay (g), and seeding the neurospheres on tissue culture-treated plastic in the classical medium (DMEM + $10 \%$ FBS) (h). (g) Calcein-AM treated GFs throughout the sphere showed bright red fluorescence indicating that they were alive. Nuclei were stained with DAPI (blue). (h) When the floating GF spheres were placed on tissue culture-treated culture dishes, they adhered to the substrate allowing the cells present in the spheres to migrate and proliferate on to the substrate to form a monolayer. The image shows outgrowth of the cells $24 \mathrm{~h}$ after initiation of the culture. Scale bars: $100 \mu \mathrm{m}(\mathbf{e}$, f and $\mathbf{g}) ; 500 \mu \mathrm{m}(\mathbf{h})$. 

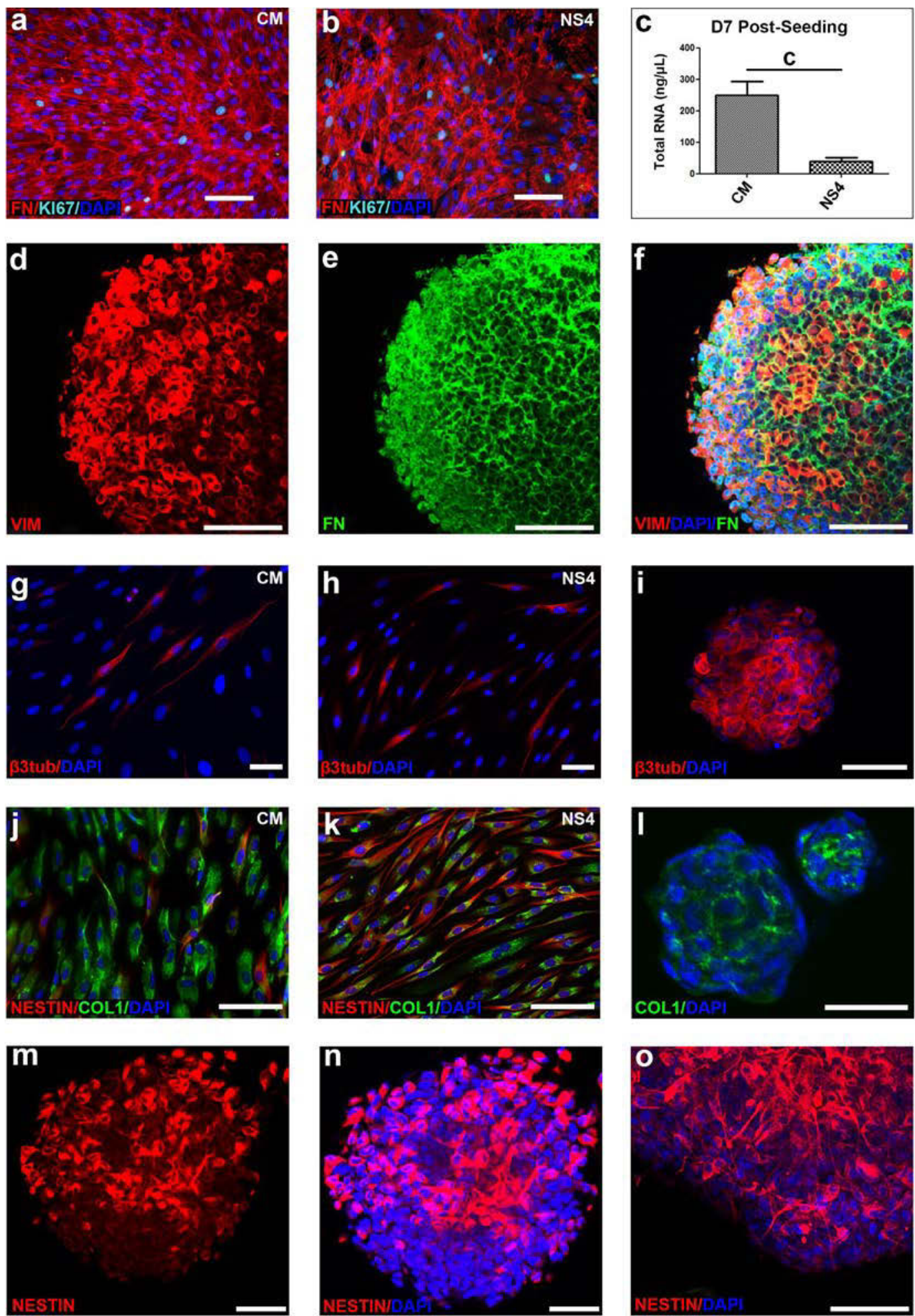

Fig. 3. Gingival fibroblasts undergo a neural phenotypic switch in NS4 medium and neurosphere culture. Figure shows analysis of cell proliferation and expression of mesenchymal/fibroblast markers fibronectin, vimentin and type I collagen, and neuronal markers $\beta 3$-tubulin and nestin in plastic-adherent monolayer and floating sphere cultures of gingival fibroblasts (GFs) generated in classical (CM; DMEM+10\% FBS) and NS4 medium after $5 \mathrm{~d}$ of induction. (a and b) Double immunostaining of fibronectin and Ki67 (a proliferation marker) in GF monolayer cultures generated in CM (a) and NS4 medium (b). (c) Comparison of GF growth by measurement of total RNA levels in plastic-adherent monolayer cultures in CM and NS4 medium $7 \mathrm{~d}$ post-seeding ( $\mathrm{c}=p<0.001$, Bonferroni test). (d-f) Double immunostaining of vimentin and fibronectin in GFs cultured as floating spheres in NS4 medium. (g-i) Immunostaining of $\beta 3$-tubulin in GFs monolayer cultures in CM (g) or NS4 medium (h), or in floating sphere culture in NS4 medium (i). (j and k) Double immunostaining of nestin and type I collagen in GFs in monolayer culture in CM (j) and NS4 medium (k). (l) Immunostaining of type I collagen in GFs cultured as floating spheres in NS4 medium. (m-o) Immunolocalisation of nestin in floating sphere GF cultures in NS4 medium. Nuclei were stained with DAPI (blue). Scale bars: $100 \mu \mathrm{m}$ (a, b, $\mathbf{d}, \mathbf{e}, \mathbf{f}, \mathbf{j}$ and $\mathbf{k}) ; 50 \mu \mathrm{m}(\mathbf{g}, \mathbf{i}, \mathbf{m}, \mathbf{n}$ and $\mathbf{o}) ; 25 \mu \mathrm{m}(\mathbf{l})$. 
a

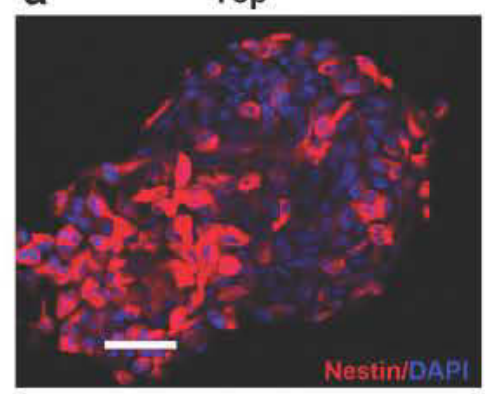

b

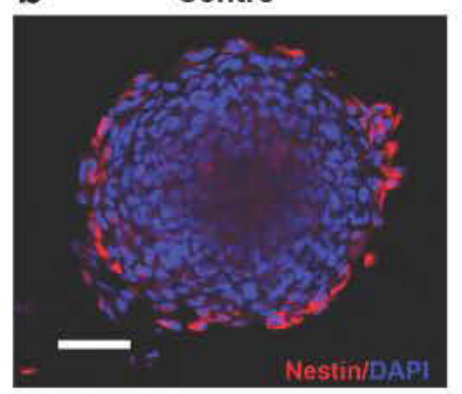

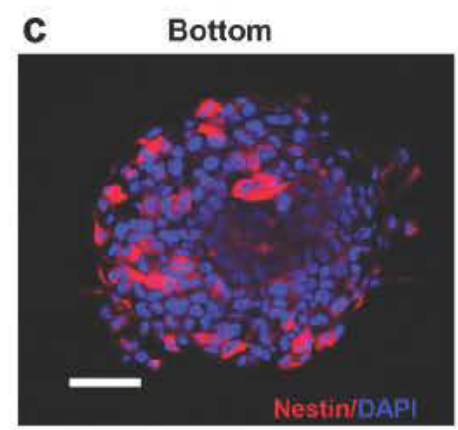

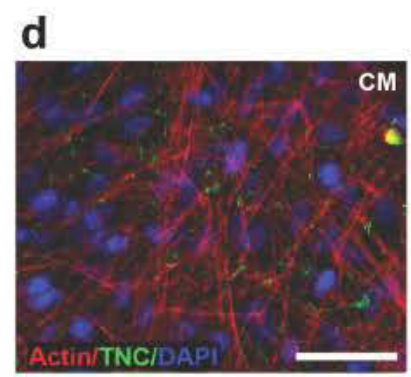

e f

g
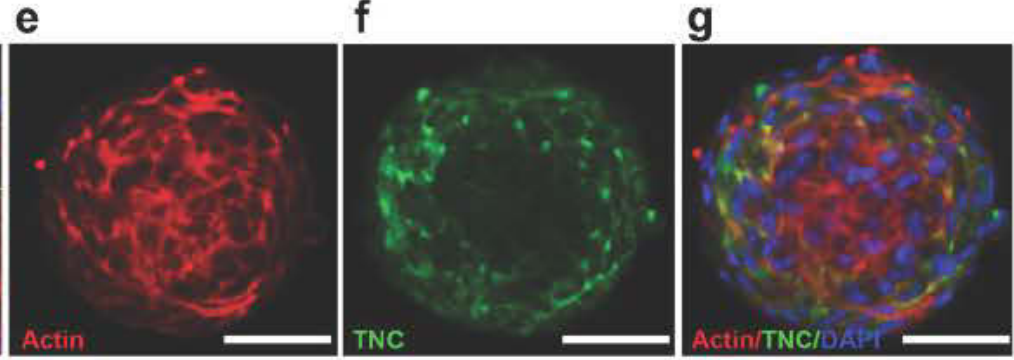

h

\section{i}
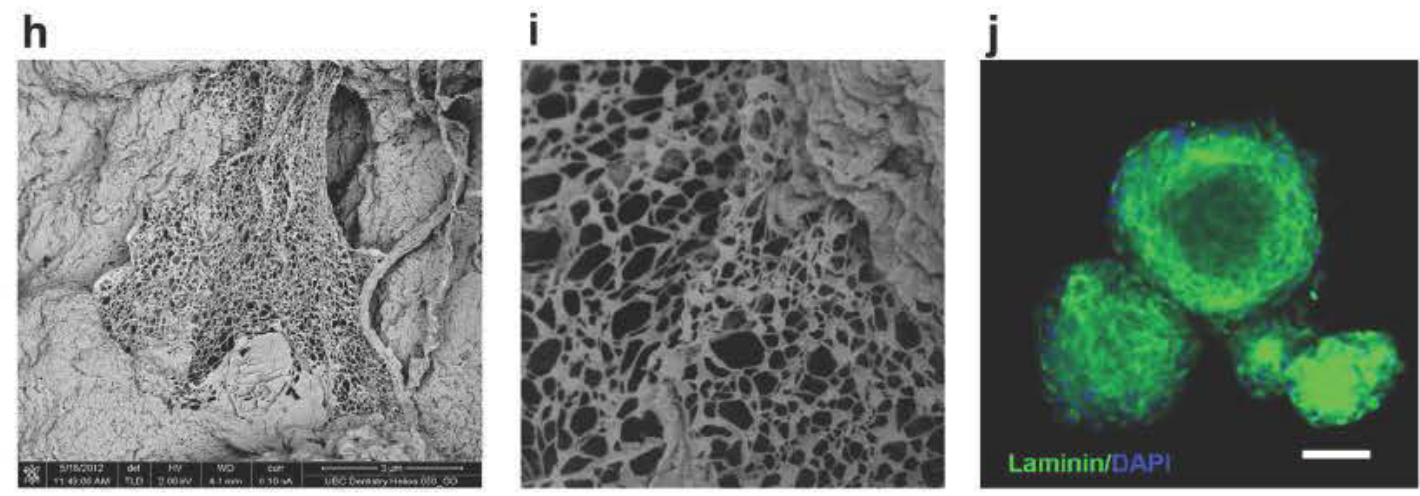

k

Under the Periphery

m Centre
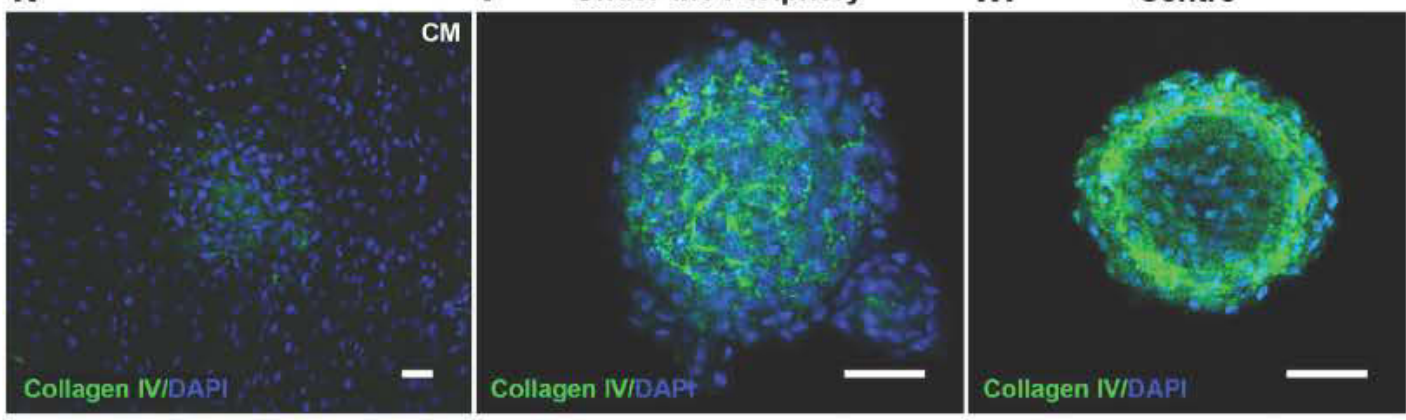

Fig. 4. Cells present on the outer surface layers of the neurospheres show distinct immunoreactivity for nestin and tenascin- $\mathrm{C}$ and are underlined by a basement membrane-like extracellular matrix. The figure shows characterisation of cell and extracellular matrix polarisation in GF-derived neurospheres generated in NS4 medium by immunostaining (a-g and $\mathbf{j}-\mathbf{m}$ ) and by scanning electron microscopy (SEM; $\mathbf{h}$ and $\mathbf{i})$. (a-c) Representative confocal fluorescence microscope images of nestin localisation at the top, middle and bottom focal planes of a neurosphere. Cells showing most abundant nestin immunoreactivity are polarised to the outer surface of the neurosphere. (d-g) Representative images of double immunostaining of actin and tenascin-C (TNC) in a neurosphere (e-g), compared to GF monolayer cultured in CM (d). Cells showed well-organised actin cytoskeleton throughout the neurosphere. Immunoreactivity for tenascin-C was very weak in monolayer cultures (d), while in the floating sphere cultures it showed strong accumulation in the cells present in the several outer layers of the spheres (f and g). (h and i) Representative low (h) and high (i) power images of SEM analysis of a neurosphere showing a basement membrane-like network structure localised beneath the artificially fractured external cell layer. (j-m) The outer part of the neurospheres showed also abundant accumulation of laminin (j) and type IV collagen (I-m), while only weak positive staining for type IV collagen was noted in few areas of GF monolayer cultures in CM (k). Nuclear DAPI staining (blue) indicated that in the largest spheres the middle part contained fewer cells (a-c), while in the smallest ones, cells were more evenly distributed (l-m). The neurospheres were processed for immunostaining and SEM $5 \mathrm{~d}$ after cell seeding. Scale bars: $50 \mu \mathrm{m}$. 

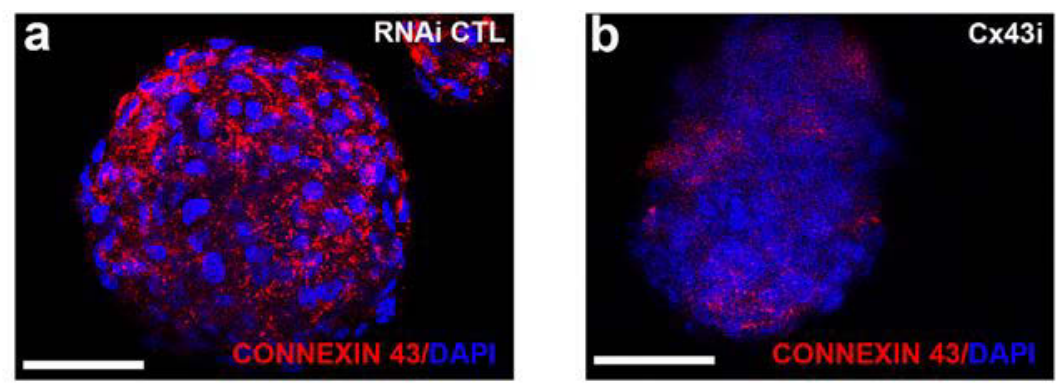

\section{C}

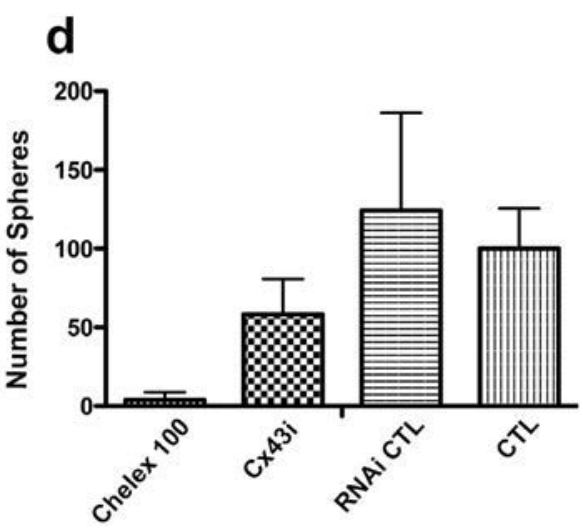

Fig. 5. Neurospheres express connexin 43 gap junction proteins that participate with calcium-dependent cell adhesions in the sphere formation. GFs were transfected with connexin 43 (Cx43) siRNA (CX43i) or control siRNA (RNAi CTL) before generation of floating spheres, and Cx43 abundance was assessed by immunostaining (a and b) and qRT-PCR (c). Immunostaining of $\mathrm{Cx} 43$ in neurospheres generated by cells treated with control siRNA showed abundant immunoreactivity of $\mathrm{Cx} 43$ throughout the sphere 5 days after seeding (a). Cx43 siRNA strongly reduced Cx43 immunoreactivity in the spheres (b). In general, spheres formed by cells transfected with Cx43 siRNA were smaller than those generated with control siRNA transfected cells (a and b). Nuclei were stained with DAPI (blue). (c) Quantification of Cx43 mRNA expression in Cx43 and control siRNA treated cells by qRT-PCR $24 \mathrm{~h}$ after transfection. Cx43 siRNA caused about $80 \%$ down regulation of the target mRNA. (d) Quantification of neurospheres formed in the presence of $\mathrm{Ca}^{2+}$ chelator $\left(\mathrm{Chelex}^{\circledR} 100\right)$ that disrupts cadherin-mediated cell-cell adhesions, or treated with $\mathrm{Cx} 43$ (CX43i) or control (RNAi CTL) siRNA, or left untreated (CTL) at day 5 post-seeding. Inhibition of cadherin function by $\mathrm{Ca}^{2+}$ chelation completely inhibited neurosphere formation, while down regulation of $\mathrm{Cx} 43$ expression by siRNA reduced the number of neurospheres by about $50 \%$. Scale bars: $50 \mu \mathrm{m}$.

the above genes were expressed by GF and GSC cultures at similar level (Fig. 1h). Taken together, both human GF and GSC cultures established from gingiva express NC signature genes in vitro.

\section{Gingival cells from monolayer cultures form floating neurospheres in suspension}

NC-derived cells cultured from tissue by the explant culture or enzymatic release methods have a distinct ability to form floating spheres, also termed neurospheres, in culture (Achilleos and Trainor, 2012). However, this has never been tested with human gingiva-derived cells. Therefore, we further assessed whether GFs and GSCs form such spheres. We first tested the ability of six previously described culture media to support sphere formation. To this end, we released GFs from the monolayer cultures and seeded them in non-tissue culture treated dishes in the different test media (Table 1), and floating sphere formation was scored after $5 \mathrm{~d}$. The results showed the highest sphere formation efficiency by NS4 medium (Fig. 2a), although this tendency was not statistically significant. Therefore, NS4 medium was chosen for the subsequent experiments. This medium has been previously used to generate neurospheres using multipotent skin-derived precursors (SKP) that also derive from the NC (Davies et al., 2010; Toma et al., 2005). Using the NS4 medium, a linear correlation was found between the number of GFs seeded and relative number of spheres formed (Fig. 2b). On the other hand, sphere formation was dependent on cell passaging in culture, as it was significantly more efficient at low $(\mathrm{P}<5)$ compared to high passage $(\mathrm{P}>5)$ (Fig. 2c). When GFs and GSCs were compared, they showed no significant differences in their ability to form spheres (Fig. 2d). Morphologically, the floating spheres formed by all studied cell lines (Fig. 2e and f) resembled the classically described neurospheres generated by NC-derived cells enzymatically released from tissue (Toma et al., 2001).

To confirm viability of the cells residing in the spheres we performed the Calcein AM viability assay. The results showed abundant fluorescent colour development in cells throughout the spheres, indicating that they were viable (Fig. 2g). To further confirm viability, the spheres were transferred to tissue culture-treated dishes, and incubated in the classical fibroblast culture medium (CM; DMEM containing $10 \%$ FBS). In these conditions, both GF (Fig. 2h) and GSC (data not shown) spheres attached to the 

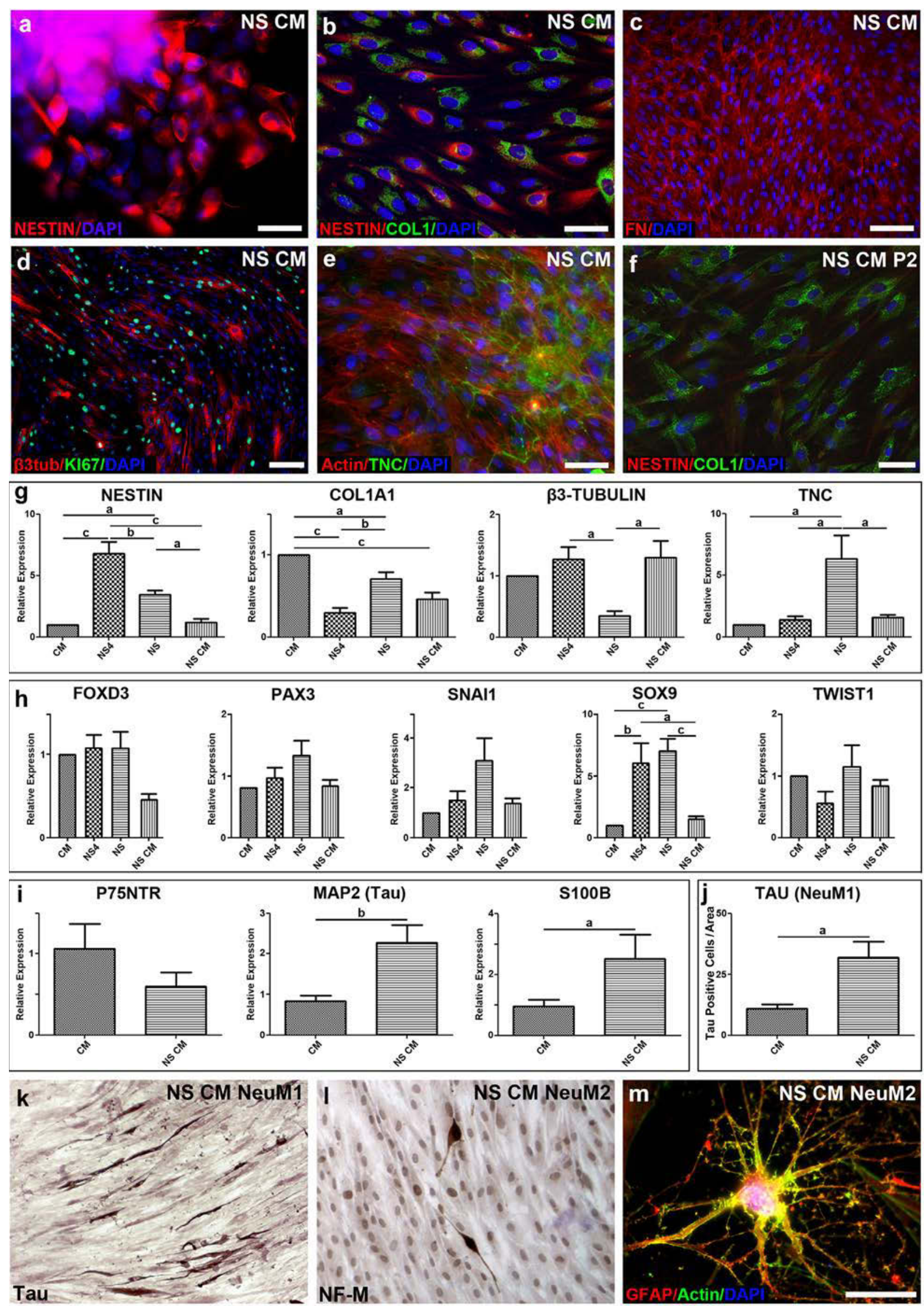

Fig. 6 (Legend on next page). 
Fig. 6 (Previous page). Cells grown out of the gingival fibroblast-generated neurospheres express neural crest and neural markers. (a-f) Neurospheres generated by GFs in NS4 medium were placed on tissue culture-treated plates in the classical medium (CM; DMEM + $10 \%$ FBS), and cells growing out of the spheres (NS CM) were analysed for expression of nestin (a and b), type I collagen (b), fibronectin (c), $\beta 3$-tubulin (d), Ki67 proliferation marker (d) and tenascin-C (e) by immunostaining $7 \mathrm{~d}$ after initiating the culture (a-e). (f) Image shows nestin and type I collagen double immunostaining after propagation of outgrown cells as monolayer culture in CM medium for two passages. (a-b) Many cells migrating out of the spheres showed strong immunoreactivity for nestin. (b) Double immunostaining with the fibroblast marker type I collagen and nestin showed that during migration, some cells that produced type I collagen showed only weak nestin immunoreactivity, while most of the nestin positive cells did not show staining for type I collagen. (c) The extracellular matrix of outgrowing cells stained strongly for fibronectin. (d) Many of the cells growing out of the spheres showed strong immunostaining for $\beta 3$-tubulin and proliferation marker Ki67. However, many of the $\beta 3$-tubulin positive cells were negative for Ki67 staining. (e) Immunoreactivity for tenascin-C was noted in the area where the spheres were attached to the plastic dish, while cells migrating out from the sphere were mostly negative. (f) Immunostaining of cells outgrown from the spheres and cultured for two passages as a monolayer culture in CM (NS CM P2). Few cells showed only weak immunoreactivity for nestin while many were positive for type I collagen. (g and h) qRT-PCR analysis of nestin, type I collagen, $\beta 3$-tubulin, tenascin-C (TNC), SNAI1, TWIST1, PAX3, SOX9 and FOXD3 mRNA expression in parental GF monolayer cultures grown in CM or in NS4 media for $7 \mathrm{~d}$, in floating neurospheres cultured in NS4 medium (NS) for $5 \mathrm{~d}$, and in cells growing out of the neurospheres in $\mathrm{CM}$ (NS CM) after $7 \mathrm{~d}(\mathrm{a}=p<0.05 ; \mathrm{b}=p<0.01$; $\mathrm{c}=p<0.001$; ANOVA, Bonferroni test). (i) qRT-PCR analysis of p75NTR, MAP2 and S100B in plastic adherent cells outgrown from the spheres and cultured in CM (NS CM) for $10 \mathrm{~d}$ compared to the parental GFs cultured in CM as monolayers $(\mathrm{CM})(\mathrm{a}=p<0.05 ; \mathrm{b}=p<0.01$; Wilcoxon test). ( $\mathbf{j}$ and $\mathbf{k})$ To induce neuronal differentiation, parental GF cultures (GF) and cells growing out of the neurospheres (NS CM) were cultured in CM supplemented with retinoic acid (NeuM1), and neuronal differentiation assessed by immunostaining of Tau after $10 \mathrm{~d}$. All cultures contained cells that were positive for Tau staining, and the number of Tau positive cells was significantly higher in the NS CM compared to $\mathrm{CM}$ cultures $(\mathbf{j})(\mathrm{a}=p<0.05$; Wilcoxon test). ( $\mathbf{l}$ and $\mathbf{~ m})$ Cells growing out of the neurospheres were cultured in the neurogenic DMEM/F12 medium supplemented with $1 \%$ N2 culture supplement and FGF2 (NeuM2), and expression of neurofilament-M (l) and Schwann cell marker GFAP (m) were assessed after three weeks by immunostaining. Scale bars: $50 \mu \mathrm{m}(\mathbf{a}, \mathbf{b}, \mathbf{e}, \mathbf{f}$ and $\mathbf{m}) ; 100 \mu \mathrm{m}(\mathbf{c}$ and $\mathbf{d})$.

culture dish followed by a rapid outgrowth of adherent cells, indicating that the spheres were composed of viable and functional cells. Thus, GFs and GSCs released from plastic-adherent monolayer cultures generate floating spheres that are composed of live cells that can be further propagated as plastic adherent cells.

\section{Neurosphere formation involves neural phenotypic switch}

To characterise the phenotype of GFs forming the floating spheres further, we compared cells maintained in CM and NS4 medium in plastic-adherent monolayer and floating sphere cultures. In monolayer cultures, both media supported cell growth as determined by the proliferation marker Ki67 immunostaining (Fig. 3a and b), although the increase in cell numbers, as indirectly determined by measuring total RNA content after $7 \mathrm{~d}$, was significantly higher in CM than in NS4 medium (Fig. 3c). Immunolocalisation demonstrated that GFs in plastic-adherent monolayer cultures produced abundantly vimentin (data not shown) and fibronectin in both the CM (Fig. 3a) and NS4 medium (Fig. 3b). These two proteins are co-expressed in various connective tissue cells, including fibroblasts and MSCs (Fournier et al., 2013). When GFs were cultured as floating spheres in NS4 medium, they maintained their immunoreactivity for vimentin and fibronectin similar to the monolayer cultures (Fig. 3df), Similar results were obtained with GSC cultures in corresponding monolayer or floating sphere cultures (data not shown).
We then assessed expression of two neural lineageassociated markers, cytoplasmic intermediate filaments $\beta 3$-tubulin and nestin, previously shown induced in neurosphere cultures (Toma et al., 2005). When GFs were maintained in $\mathrm{CM}$ in monolayer cultures, only few cells were positive for $\beta 3$-tubulin (Fig. 3g) and nestin (Fig. $3 \mathbf{j})$. However, switching cells into the NS4 medium in monolayer cultures caused a significant increase in nestin mRNA expression (Fig. 6l) and in the number of nestin positive cells in the cultures (Fig. 3k). This was associated with a significant reduction of mRNA expression (Fig. 6l) and immunoreactivity for type I collagen (Fig. 3j and k), a marker for fibroblast phenotype, in the cultures. In monolayer cultures in both CM and NS4 medium, individual cells were heterogeneous in nestin and type I collagen immunoreactivity as some showed staining for only nestin or collagen and some were positive for both (Fig. 3j and $\mathbf{k}$ ). In contrast to nestin and type I collagen, switching from CM to NS4 medium did not have a marked effect in the number of $\beta 3$-tubulin positive cells (Fig. 3g and $\mathbf{h}$ ), or $\beta 3$-tubulin mRNA expression (Fig. 6l). However, when the cells were cultured in NS4 medium as floating spheres, most spheres showed abundant immunoreactivity for 33 -tubulin (Fig. 3l) and nestin (Fig. 3m-o). While the floating spheres showed some cells positive for type I collagen immunostaining (Fig. 3l), similar to monolayer cultures in NS4 medium, expression of collagen mRNA in floating spheres remained significantly lower as compared with the monolayer cultures in CM (Fig. 6l). 
Taken together, in gingival cells, expression of fibronectin and vimentin, two proteins produced by fibroblasts and MSCs, and neural-related $\beta 3$-tubulin is independent of the culture medium, and is retained in the floating sphere cultures. However, switching from the CM to NS4 medium in monolayer cultures induces expression of nestin, while suppressing expression of the fibroblast-specific type I collagen. This NS4 mediuminduced phenotypic switch is maintained when cells are propagated in the floating sphere cultures.

\section{Neurosphere formation involves cell and extracellular matrix polarisation in the spheres}

Next, we performed a more detailed analysis of organisation and polarisation of key neurosphere molecules in the floating spheres by using confocal fluorescence microscopy (Fig. 4). Examination of distribution of DAPI-stained nuclei by using optical sections from top, centre and bottom planes of the spheres was used to assess cell distribution within the spheres. In the largest spheres the middle part contained fewer cells (Fig. 4a-c), while in the smallest ones, cells were rather evenly distributed (Fig. $4 \mathbf{I}$ and m). Visualisation of actin distribution also demonstrated presence of cells with well-organised filamentous actin cytoskeleton throughout the smaller spheres (Fig. 4e and g). Interestingly, the nestin positive cells were concentrated on the outer surface of the GF (Fig. 4a-c) and GSC (data not shown) spheres. Tenascin-C (Fig. $4 \mathbf{f}$ and g), a molecule involved in NC migration (Tucker, 2001), and basement membrane components laminins (Fig. 4j) and type IV collagen (Fig. 4I-m) were most strongly localised in the surface layers of the spheres. In contrast, tenascin-C (Fig. 4d) and type IV collagen (Fig. 4k) were practically absent from monolayer cultures in CM. The above molecules, and fibronectin that also accumulated strongly in the spheres (Fig. 1, 3e and $\mathbf{f}$ ), are abundantly present in embryonic NC extracellular matrix (ECM) (Hall, 1999). Morphological characterisation of the spheres by scanning electron microscopy demonstrated a net-like ECM structure underneath the surface cell layers (Fig. $4 \mathbf{h}$ and i).

Taken together, culture of GFs and GSCs in floating spheres in NS4 medium causes polarisation of the nestinpositive cells to the outer surface of the spheres. This is associated with accumulation of an ECM underneath the polarised nestin-positive cell layer that has molecular composition and organisation that resembles basement membrane, and contains fibronectin and tenascin- $\mathrm{C}$, reminiscent of ECM involved in embryonic $\mathrm{NC}$ migration (Hall, 1999). Thus, floating sphere cultures induced an organotypic cellular and molecular polarisation distinct from monolayer cultures.

\section{Neurosphere formation is regulated by connexin 43 and calcium-dependent cell-cell communication}

In classical neurosphere cultures formed by neural progenitors, cells form abundant connexin 43 (Cx43)mediated gap junctions that may aid their intercellular communication and sphere formation (Duval et al., 2002). Therefore, we wanted to explore cell-cell contacts in the floating spheres from GFs. We have shown previously that GFs form Cx43-mediated gap-junctions in monolayer cultures (Tarzemany et al., 2015). Accordingly, GFs cultured in the floating spheres showed abundant punctate Cx43 staining (Fig. 5a) typical to $\mathrm{Cx} 43$ gap-junction plaques (Tarzemany et al., 2015). In order to find out whether $\mathrm{Cx} 43$ was important for the sphere formation, we suppressed its expression by siRNA, which resulted to about $80 \%$ down regulation of $\mathrm{Cx} 43 \mathrm{mRNA}$ expression (Fig. 5c), and to a strong reduction in $\mathrm{Cx} 43$ immunoreactivity in the spheres (Fig. 5b). Cx43 down regulation caused a $60 \%$ decrease in the number of spheres formed after $5 \mathrm{~d}$ (Fig. 5d), reduced their size and resulted to a less well-defined sphere organisation and morphology (Fig. 5a and b). In addition to connexins, cadherins, $\mathrm{Ca}^{2+}$-dependent cell-cell adhesion molecules, are crucial for NC cells (Taneyhill and Schiffmacher, 2013). Therefore, we inhibited cadherinmediated cell-cell contacts by reducing culture medium $\mathrm{Ca}^{2+}$ concentration by a $\mathrm{Ca}^{2+}$ chelator $\left(\mathrm{Chelex}^{\circledR} 100\right)$ during sphere formation. Chelation of $\mathrm{Ca}^{2+}$ completely inhibited sphere formation (Fig. 5d). Thus, cell-cell communication mediated by $\mathrm{Cx} 43$ and $\mathrm{Ca}^{2+}$-dependant cell-cell junctions, likely representing cadherins, are critical for gingival cell floating sphere formation.

\section{Neural crest/neural gene expression and differentiation of floating sphere-derived cells}

In order to assess if the cells within the floating spheres possessed differentiation capacity as described for SKP neurospheres (Toma et al., 2001), we transferred them to tissue culture-treated dishes and cultured them in $\mathrm{CM}$ (DMEM $+10 \%$ FBS). Within a few hours, the spheres attached to the dishes and cells began to migrate out (Fig. 6a), as has been described for neural progenitor neurospheres (Jacques et al., 1998). The first migrating cells were strongly positive for nestin immunostaining (Fig. $6 \mathbf{a}$ and $\mathbf{b})$. In addition, cells positive for type I collagen, fibronectin and $\beta 3$-tubulin were detected in the cultures (Fig. 6b-d). Interestingly, the type I collagen positive cells appeared to be mostly negative for nestin, while cells strongly positive for nestin did not stain for type I collagen (Fig. 6b). Many of the migrating cells also showed positive nuclear staining for the proliferation marker Ki67 (Fig. 6d). However, double immunostaining suggested that most of the $\beta 3$-tubulin positive cells present in the outgrowths were not proliferating (Fig. 6d). Tenascin C, which was strongly expressed in the outer layer of the spheres, was detected at the point where the sphere attached to the plastic dish, but was mostly absent from the cells migrating out of the sphere (Fig. 6e). Thus, cells outgrowing from the spheres produced nestin (Fig. 6a and b) and $\beta 3$ tubulin (Fig. 6d), while their parental cultures not subjected to floating sphere formation were mostly negative for these molecules in the same condition (monolayer culture in CM) (Fig. 3g). Further propagation and passaging of the outgrown cells as monolayer cultures in CM showed, however, that the highly nestin (Fig. 6f) and $\beta 3$-tubulin (data not shown) positive cell populations were lost once the cells had been passaged twice, while an increase in the number of cells positive for type I collagen was observed (Fig. 6f).

To compare the effect of culture conditions on cell phenotype in more detail, we performed qRT-PCR to assess expression of $\mathrm{NC}$ and neuronal genes in the parental 
monolayer GFs cultured in CM or in NS4 for $7 \mathrm{~d}$, in floating spheres in NS4 medium for $5 \mathrm{~d}$ (NS), or $7 \mathrm{~d}$ after spheres were reseeded to grow as plastic adherent cells in CM (NS $\mathrm{CM})$. Results showed that floating spheres grown in NS4 medium (NS) expressed significantly greater levels of nestin, tenascin-C and SOX9 as compared to CM and NS $\mathrm{CM}$ cultures (Fig. $6 \mathbf{g}$ and $\mathbf{h}$ ), while there were no significant differences in the levels of FOXD3, PAX3, SNAI1 and TWIST1 expression (Fig. 6h). When cells cultured in NS4 medium as monolayer or neurosphere cultures were compared, the sphere culture induced an upregulation of $\mathrm{NC}$-associated tenascin-C and down regulation of nestin and $\beta 3$ tubulin (Fig. 6g). In contrast to the above NC and neuronal signature genes, the mesenchymal/fibroblast marker type 1 collagen was strongly down regulated in NS4, NS and NS CM cultures as compared to CM cultures (Fig. 6g). Thus, the findings show that monolayer and floating sphere culture of NC-like GFs and GSCs in NS4 medium induces and/or enriches cells with NClike phenotype. Together with the above data showing striking spatial polarisation of several proteins, including tenascin-C and nestin, within the neurospheres (Fig. 4), the gene expression changes occurring in neurosphere cultures suggest that the floating sphere culture distinctly further modulates phenotype of GF subpopulations within the spheres.

In order to further assess their neural characteristics, parental monolayer GF cultures and cells grown out of the spheres (NS CM) were treated with trans-retinoic acid in CM (NeuM1) (Gong et al., 2013), and expression of neuronal marker Tau was assessed by immunostaining (Fig. $6 \mathbf{k})$. After $10 \mathrm{~d}$, cultures contained cells that had a narrow elongated morphology and showed positive staining for Tau, but the number of positive cells in NS CM cultures was significantly greater than in CM cultures (Fig. 6j). To further assess the phenotype of NS CM cells, we cultured them in the presence of another neurogenic medium (DMEM/F12 supplemented with $1 \%$ N2 culture supplement and FGF2; NeuM2) and assessed the expression of neurofilament-M (another neuronal marker) and GFAP (a glial/Schwann cell marker) by immunostaining (Fig. $6 \mathbf{l}$ and $\mathbf{m}$ ). After three weeks, elongated neurofilament-M positive cells had appeared on top of the underlying negative cells (Fig. 6l). In addition, scattered cells with a distinct stellate morphology were positive for GFAP (Fig. 6m). This is similar to what has been described for SKP cultures that have undergone neural differentiation (Toma et al., 2005). Thus, gingival cells outgrown from the floating spheres (NS $\mathrm{CM}$ ) maintained their distinct phenotype transiently, and under neural-differentiation conditions generated cells with neural morphologies, and showed positive immunostaining for neural markers Tau, neurofilament-M and GFAP.

To further assess neural differentiation, we performed qRT-PCR of neuronal (MAP2) and Schwann cell (S100B and p75NTR) marker genes in the parental monolayer cultures in $\mathrm{CM}$, and in sphere-derived cells that were reseeded to grow as plastic adherent cells in CM (NS CM) for $10 \mathrm{~d}$ (Fig. 6i). Results showed that cells derived from spheres (NS CM) expressed significantly greater levels of MAP2 and S100B as compared to the CM cultures (Fig. 6i). Thus, propagation of cells in the floating neurospheres promoted their neural differentiation potential.

\section{Discussion}

Use of NC-derived cells has been hampered due to their rarity in adult tissues, and their complex isolation process. Furthermore, the abundance of these cells in tissues decreases during aging (Hunt et al., 2009). Previous studies have suggested that gingival tissue derives from the NC and harbours abundantly cells with NC-like properties (Marynka-Kalmani et al., 2010; Widera et al., 2009; Xu et al., 2013). Particularly, findings from juvenile (8-weeks-old) NC-reporter mice showed that NC-derived cells were present in the gingival connective tissue, and represented the majority of cells within CFU-F colonies generated by the cells cultured from the tissue ( $\mathrm{Xu}$ et al., 2013). Our findings from 8-months-old Wnt1-Cre/ R26RYFP NC-reporter mice demonstrated that gingival connective tissue still contained abundantly NC-derived cells also in these much older animals. Therefore, aging may not have a dramatic effect on the abundance of these cells in gingiva. In support of this, a recent study reported that the expression of pluripotency-associated genes and multipotent differentiation capacity is similar in gingival cells isolated from young and old human donors (MarynkaKalmani et al., 2010).

Isolation and enrichment of neural progenitors and NC-derived cells has been classically performed with cells enzymatically released directly from the tissue, and then culturing them in suspension in a serum-free medium supplemented with mitogens where cells aggregate to form floating spheres (also called neurospheres) (Gil-Perotin et al., 2013; Pastrana et al., 2011). This protocol may selectively enrich a distinct cell population from the tissue or allow the cells to maintain or acquire a distinct phenotype that might be lost during the standard culture of plasticadherent cells in serum containing medium (Pastrana et al., 2011). The challenge with this protocol is to release adequate numbers of the rare NC-derived cells from the tissues. One approach to eliminate this problem is to first expand the cells in culture before subjecting them to the neurosphere generation. Therefore, we tested whether the gingival cells maintained in the standard serum-containing medium as plastic-adherent cultures express NC-related genes, and whether they generate floating neurospheres and possess neural differentiation potential, key characteristics described for NC-derived stem cells (Calderone, 2012; Toma et al., 2001). For the experiments, we used both parental fibroblast cultures (GFs) and pooled CFU-F populations (GSC) from these cultures. Pooled CFU-F populations of human gingival cells contain progenitor cells with multipotent differentiation potential (Fournier et al., 2013), although these properties can also be found in non-selected human gingival fibroblast cultures (Häkkinen et al., 2014; Marynka-Kalmani et al., 2010). Accordingly, our findings showed that both GF and GSC cultures expressed nestin, a cytoskeletal molecule present in neural progenitor/stem cells (Calderone, 2012), and Snai1, Twist1, 
Pax3, Sox9 and FoxD3, transcription factors typical to NCprogenitors (Kaltschmidt et al., 2012). A distinct feature of NC-related cells is that they form floating spheres in the presence of EGF and FGF2 (Calderone, 2012; Dupin and Coelho-Aguiar, 2013). The findings showed that GFs and GSCs released from plastic-adherent cultures generated these spheres in the serum-free medium containing the above factors. Gingival neurosphere formation depended on expression and function of $\mathrm{Cx} 43$, a molecule also found in early migratory $\mathrm{NC}$ cells and NC-derived progenitor cells where it regulates their neurosphere formation ability (Curchoe et al., 2010; Duval et al., 2002; Pelaez et al., 2013). Furthermore, gingival neurosphere formation was totally calcium-dependent suggesting involvement of cadherins that require calcium for proper function. Cadherins regulate NC development and neurosphere formation by neural progenitors, and can be used as a target to selectively isolate these cells (Taneyhill, 2008; Yagita et al., 2009; Zhou and Snead, 2008). Thus, our findings indicate that the human gingival cell populations are enriched with NC-like cells capable of neurosphere formation in vitro.

Interestingly, cells in the neurospheres showed significantly increased expression of $\mathrm{NC}$ and neural progenitor-related genes, including nestin, tenascin-C and Sox9, while they displayed down regulation of fibroblast-related type I collagen, when compared to standard monolayer cultures. Thus, cellular niche in the neurospheres further promoted the NC-like phenotype of the cells. Alternatively, the sphere formation selected cells with NC-properties, while suppressing the mesenchymal phenotype (type I collagen expressing) out of the heterogeneous parental populations. Interestingly, the phenotypic switch characterised by elevated expression of nestin and SOX9 and down regulation of type I collagen, was also achieved by incubating the monolayer cultures in the NS4 medium, suggesting that gingival cells can acquire an enhanced NC-like phenotype in plastic adherent cultures when appropriately stimulated without the need for the neurosphere culture step.

In order to assess in more detail the phenotype of neurosphere-associated cells, we analysed them structurally. Remarkably, in the gingival cell-derived neurospheres, the nestin positive cells were polarised to the outer layers and were surrounded and underlined with an ECM that was rich in molecules typical to embryonic NC and believed to support NC migration (Hall, 1999), namely fibronectin, laminin, type IV collagen and tenascin-C. Thus, gingival cells placed in neurosphere cultures generate an autogenous ECM niche that recapitulates some of the features found in the embryonic tissue. This niche maybe critical to maintain the NC-like phenotype of the gingival neurosphere-associated cells as propagation and serial passaging of neurosphere-derived cells in their standard medium in a monolayer culture resulted to a loss of their phenotype. In any case, initially, when placed in plastic adherent cultures, the neurosphere-derived cells generated a plastic adherent, proliferating population that contained two distinct populations of cells. These were composed of cells that were either positive for nestin or type I collagen immunoreactivity, respectively, suggesting that the cell population contained distinct NC-like cells (nestin + ) and fibroblastic (type I collagen + ) cells. These neurospherederived cells showed an increased expression of neuronal MAP2 and of the Schwann cell-related S100B markers, and when they were further cultured in distinct neurogenic differentiation media, they generated Tau, neurofilament-M and GFAP positive cells, suggesting neural differentiation potential (Svendsen et al., 2001). The frequency of Taupositive cells in the neurosphere-derived cultures was significantly higher than in the standard cultures implying that neurosphere generation protocol enhanced neuronal differentiation potential of the gingival cells.

There is ample experimental evidence that skin contains so-called skin-derived precursors (SKPs) (Hunt et al., 2009). SKPs can be generated from enzymatically released cells by subjecting them directly upon release to a floating sphere culture in medium containing EGF and FGF2 (Fernandes et al., 2004). Recently, cells with similar properties were also isolated from established skin cell cultures (Hill et al., 2012). SKPs compose a small subpopulation of cells most commonly found in NCderived skin compartments, such as facial hair follicles and express NC-related genes, including nestin, Snai1, Twist, Pax 3 and Sox9. Furthermore, when cells grown out from the floating SKP spheres were stimulated appropriately they underwent neural and mesenchymal multi-lineage differentiation (Fernandes et al., 2004; Fernandes et al., 2008; Hunt et al., 2009; Toma et al., 2001). Thus, human gingival cells from standard plastic adherent cultures and SKPs from skin may share similar NC phenotype and neural differentiation potential. Therefore, our findings suggest that standard non-selected and CFU-F-selected human gingival progenitor cell cultures contain NC-like cells with distinct NC-like differentiation potential, and may provide an easy source of these cells via enrichment by floating sphere cultures for various applications. For instance, gingiva is a particularly attractive source for cell therapy, as the tissue is easily accessible without the need for tooth extraction, and tissue discards are common during routine dental procedures. In addition, unlike in skin, wound healing in gingiva is fast and does not result in scar formation, and donors experience very little morbidity (Fournier et al., 2013; Häkkinen et al., 2014). In addition to the therapeutic applications, gingival cells may provide a novel tool to study mechanisms of NC-like differentiation and diseases affecting $\mathrm{NC}$ derivatives.

\section{Acknowledgements}

Supported by Canadian Institutes of Health Research (CIHR), Agence Nationale de la Recherche (ANR) grant SVSE 1-2012 "osteodiversity" and "gueules cassées" foundation. We thank Dr. Fabio Rossi (University of British Columbia, Vancouver, BC, Canada) for providing the transgenic mice for the study. We thank the "Cytometry and Cell Image Center" of the Cordelier Research Center and especially C. Klein for his technical expertise. The antibodies HFN 7.1, E7 and RT97 developed by Klebe RJ, Klymkowsky $\mathrm{M}$ and Wood J, respectively, were obtained from the Developmental Studies Hybridoma 
Bank, created by the NICHD of the NIH and maintained at The University of Iowa, Department of Biology, Iowa City, IA 52242, USA.

\section{References}

Abe S, Hamada K, Miura M, Yamaguchi S (2012) Neural crest stem cell property of apical pulp cells derived from human developing tooth. Cell Biol Int 36: 927-936.

Achilleos A, Trainor PA (2012) Neural crest stem cells: discovery, properties and potential for therapy. Cell Res 22: 288-304.

Arthur A, Rychkov G, Shi S, Koblar SA, Gronthos S (2008) Adult human dental pulp stem cells differentiate toward functionally active neurons under appropriate environmental cues. Stem Cells 26: 1787-1795.

Barbu M, Ziller C, Rong PM, Le Douarin NM (1986) Heterogeneity in migrating neural crest cells revealed by a monoclonal antibody. J Neurosci 6: 2215-2225.

Calderone A (2012) Nestin+ cells and healing the infarcted heart. Am J Physiol Heart Circ Physiol 302: H1-9.

Chai Y, Jiang X, Ito Y, Bringas P Jr, Han J, Rowitch DH, Soriano P, McMahon AP, Sucov HM (2000) Fate of the mammalian cranial neural crest during tooth and mandibular morphogenesis. Development 127: 1671-1679.

Crane JF, Trainor PA (2006) Neural crest stem and progenitor cells. Annu Rev Cell Dev Biol 22: 267-286.

Curchoe CL, Maurer J, McKeown SJ, Cattarossi G, Cimadamore F, Nilbratt M, Snyder EY, Bronner-Fraser M, Terskikh AV (2010) Early acquisition of neural crest competence during hESCs neuralization. PLoS One 5: e13890.

Davies LC, Locke M, Webb RD, Roberts JT, Langley M, Thomas DW, Archer CW, Stephens P (2010) A multipotent neural crest-derived progenitor cell population is resident within the oral mucosa lamina propria. Stem Cells Dev 19: 819-830.

Dong R, Liu X, Fan M, Yang L, Peng L, Zhang L (2010) Isolation and differentiation of nestin positive cells from rat oral mucosal lamina propria. Differentiation 79: 9-14.

Dupin E, Calloni G, Real C, Goncalves-Trentin A, Le Douarin NM (2007) Neural crest progenitors and stem cells. C R Biol 330: 521-529.

Dupin E, Coelho-Aguiar JM (2013) Isolation and differentiation properties of neural crest stem cells. Cytometry A 83: 38-47.

Dupin E, Sommer L (2012) Neural crest progenitors and stem cells: from early development to adulthood. Dev Biol 366: 83-95.

Durand E, Fournier B, Couty L, Lemitre M, Achouh P, Julia P, Trinquart L, Fabiani JN, Seguier S, Gogly B, Coulomb B, Lafont A (2012) Endoluminal gingival fibroblast transfer reduces the size of rabbit carotid aneurisms via elastin repair. Arterioscler Thromb Vasc Biol 32: 1892-1901.

Duval N, Gomes D, Calaora V, Calabrese A, Meda P, Bruzzone R (2002) Cell coupling and Cx43 expression in embryonic mouse neural progenitor cells. J Cell Sci 115: 3241-3251.
Fernandes KJ, McKenzie IA, Mill P, Smith KM, Akhavan M, Barnabe-Heider F, Biernaskie J, Junek A, Kobayashi NR, Toma JG, Kaplan DR, Labosky PA, Rafuse V, Hui CC, Miller FD (2004) A dermal niche for multipotent adult skin-derived precursor cells. Nat Cell Biol 6: 1082-1093.

Fernandes KJ, Toma JG, Miller FD (2008) Multipotent skin-derived precursors: adult neural crest-related precursors with therapeutic potential. Philos Trans R Soc Lond B Biol Sci 363: 185-198.

Fournier BP, Ferre FC, Couty L, Lataillade JJ, Gourven M, Naveau A, Coulomb B, Lafont A, Gogly B (2010) Multipotent progenitor cells in gingival connective tissue. Tissue Eng Part A 16: 2891-2899.

Fournier BP, Larjava H, Häkkinen L (2013) Gingiva as a source of stem cells with therapeutic potential. Stem Cells Dev 22: 3157-3177.

Gago N, Perez-Lopez V, Sanz-Jaka JP, Cormenzana P, Eizaguirre I, Bernad A, Izeta A (2009) Age-dependent depletion of human skin-derived progenitor cells. Stem Cells 27: 1164-1172.

Gammill LS, Bronner-Fraser M (2003) Neural crest specification: migrating into genomics. Nat Rev Neurosci 4: 795-805.

Ganz J, Arie I, Buch S, Zur TB, Barhum Y, Pour S, Araidy S, Pitaru S, Offen D (2014) Dopaminergiclike neurons derived from oral mucosa stem cells by developmental cues improve symptoms in the hemiparkinsonian rat model. PLoS One 9: e100445.

Gil-Perotin S, Duran-Moreno M, Cebrian-Silla A, Ramirez M, Garcia-Belda P, Garcia-Verdugo JM (2013) Adult neural stem cells from the subventricular zone: a review of the neurosphere assay. Anat Rec (Hoboken) 296: 1435-1452.

Glim JE, van Egmond M, Niessen FB, Everts V, Beelen RH (2013) Detrimental dermal wound healing: what can we learn from the oral mucosa? Wound Repair Regen 21: 648-660.

Gong M, Bi Y, Jiang W, Zhang Y, Chen L, Hou N, Chen J, Li T (2013) Retinoic acid receptor beta mediates all-trans retinoic acid facilitation of mesenchymal stem cells neuronal differentiation. Int J Biochem Cell Biol 45: 866-875.

Häkkinen L, Larjava H, Fournier BP (2014) Distinct phenotype and therapeutic potential of gingival fibroblasts. Cytotherapy 16: 1171-1186.

Hall BK (1999) The neural crest in development and evolution. Springer-Verlag New York Inc.

Hill RP, Gledhill K, Gardner A, Higgins CA, Crawford H, Lawrence C, Hutchison CJ, Owens WA, Kara B, James SE, Jahoda CA (2012) Generation and characterization of multipotent stem cells from established dermal cultures. PLoS One 7: e50742.

Hunt DP, Jahoda C, Chandran S (2009) Multipotent skin-derived precursors: from biology to clinical translation. Curr Opin Biotechnol 20: 522-530.

Ibarretxe G, Crende O, Aurrekoetxea M, GarciaMurga V, Etxaniz J, Unda F (2012) Neural crest stem cells from dental tissues: a new hope for dental and neural regeneration. Stem Cells Int 2012: 103503. 
Jacques TS, Relvas JB, Nishimura S, Pytela R, Edwards GM, Streuli CH, ffrench-Constant C (1998) Neural precursor cell chain migration and division are regulated through different beta1 integrins. Development 125: 3167 3177 .

Jinno H, Morozova O, Jones KL, Biernaskie JA, Paris M, Hosokawa R, Rudnicki MA, Chai Y, Rossi F, Marra MA, Miller FD (2010) Convergent genesis of an adult neural crest-like dermal stem cell from distinct developmental origins. Stem Cells 28: 2027-2040.

Jung S, Sen A, Rosenberg L, Behie LA (2010) Identification of growth and attachment factors for the serum-free isolation and expansion of human mesenchymal stromal cells. Cytotherapy 12: 637-657.

Kaltschmidt B, Kaltschmidt C, Widera D (2012) Adult craniofacial stem cells: sources and relation to the neural crest. Stem Cell Rev 8: 658-671.

Kawanabe N, Murata S, Murakami K, Ishihara Y, Hayano S, Kurosaka H, Kamioka H, Takano-Yamamoto $\mathrm{T}$, Yamashiro T (2010) Isolation of multipotent stem cells in human periodontal ligament using stage-specific embryonic antigen-4. Differentiation 79: 74-83.

Kobayashi K, Suzuki T, Nomoto Y, Tada Y, Miyake M, Hazama A, Nakamura T, Omori K (2007) Potential of heterotopic fibroblasts as autologous transplanted cells for tracheal epithelial regeneration. Tissue Eng 13: 2175-2184.

Kuznetsov SA, Friedenstein AJ, Robey PG (1997) Factors required for bone marrow stromal fibroblast colony formation in vitro. Br J Haematol 97: 561-570.

La Noce M, Mele L, Tirino V, Paino F, De Rosa A, Naddeo P, Papagerakis P, Papaccio G, Desiderio V (2014) Neural crest stem cell population in craniomaxillofacial development and tissue repair. Eur Cell Mater 28: 348-357.

Le Douarin NM (2012) Piecing together the vertebrate skull. Development 139: 4293-4296.

Le Douarin NM, Calloni GW, Dupin E (2008) The stem cells of the neural crest. Cell Cycle 7: 1013-1019.

Le Lièvre CS and Le Douarin NM (1975) Mesenchymal derivatives of the neural crest: analysis of chimaeric quail and chick embryos. J Embryol Exp Morphol 34: 125-154.

Lemos DR, Paylor B, Chang C, Sampaio A, Underhill TM, Rossi FM (2012) Functionally convergent white adipogenic progenitors of different lineages participate in a diffused system supporting tissue regeneration. Stem Cells 30: 1152-1162.

Marynka-Kalmani K, Treves S, Yafee M, Rachima H, Gafni Y, Cohen MA, Pitaru S (2010) The lamina propria of adult human oral mucosa harbors a novel stem cell population. Stem Cells 28: 984-995.

Nagoshi N, Shibata S, Kubota Y, Nakamura M, Nagai Y, Satoh E, Morikawa S, Okada Y, Mabuchi Y, Katoh H, Okada S, Fukuda K, Suda T, Matsuzaki Y, Toyama Y, Okano H (2008) Ontogeny and multipotency of neural crest-derived stem cells in mouse bone marrow, dorsal root ganglia, and whisker pad. Cell Stem Cell 2: 392-403.

Pastrana E, Silva-Vargas V, Doetsch F (2011) Eyes wide open: a critical review of sphere-formation as an assay for stem cells. Cell Stem Cell 8: 486-498.

Pelaez D, Huang CY, Cheung HS (2013) Isolation of pluripotent neural crest-derived stem cells from adult human tissues by connexin-43 enrichment. Stem Cells Dev 22: 2906-2914.

Price FM, Taylor WG, Camalier RF, Sanford KK (1983) Approaches to enhance proliferation of human epidermal keratinocytes in mass culture. J Natl Cancer Inst 70: 853861 .

Sieber-Blum M, Grim M, Hu YF, Szeder V (2004) Pluripotent neural crest stem cells in the adult hair follicle. Dev Dyn 231: 258-269.

Siegel RJ (1985) Palatal grafts for eyelid reconstruction. Plast Reconstr Surg 76: 411-414.

Stevens A, Zuliani T, Olejnik C, LeRoy H, Obriot H, Kerr-Conte J, Formstecher P, Bailliez Y, Polakowska RR (2008) Human dental pulp stem cells differentiate into neural crest-derived melanocytes and have label-retaining and sphere-forming abilities. Stem Cells Dev 17: 11751184.

Svendsen CN, Bhattacharyya A, Tai YT (2001) Neurons from stem cells: preventing an identity crisis. Nat Rev Neurosci 2: 831-834.

Swierenga SH, Auersperg N (1982) Proliferation in low calcium medium as a marker for malignancy: an apparent exception among human carcinoma cells. Cancer Lett 15: 179-183.

Taneyhill LA (2008) To adhere or not to adhere: the role of Cadherins in neural crest development. Cell Adh Migr 2: 223-230.

Taneyhill LA, Schiffmacher AT (2013) Cadherin dynamics during neural crest cell ontogeny. Prog Mol Biol Transl Sci 116: 291-315.

Tarzemany R, Jiang G, Larjava H, Häkkinen L (2015) Expression and function of connexin 43 in human gingival wound healing and fibroblasts. PLoS One 10: e0115524.

Techawattanawisal W, Nakahama K, Komaki M, Abe M, Takagi Y, Morita I (2007) Isolation of multipotent stem cells from adult rat periodontal ligament by neurosphereforming culture system. Biochem Biophys Res Commun 357: 917-923.

Teng L, Labosky PA (2006) Neural crest stem cells. Adv Exp Med Biol 589: 206-212.

Toma JG, Akhavan M, Fernandes KJ, Barnabe-Heider F, Sadikot A, Kaplan DR, Miller FD (2001) Isolation of multipotent adult stem cells from the dermis of mammalian skin. Nat Cell Biol 3: 778-784.

Toma JG, McKenzie IA, Bagli D, Miller FD (2005) Isolation and characterization of multipotent skin-derived precursors from human skin. Stem Cells 23: 727-737.

Tucker RP (2001) Abnormal neural crest cell migration after the in vivo knockdown of tenascin-C expression with morpholino antisense oligonucleotides. Dev Dyn 222: 115119.

Weber M, Apostolova G, Widera D, Mittelbronn M, Dechant G, Kaltschmidt B, Rohrer H (2015) Alternative generation of CNS neural stem cells and PNS derivatives from neural crest derived peripheral stem cells. Stem Cells 33: $574-588$.

Weinberg DA, Tham V, Hardin N, Antley C, Cohen AJ, Hunt K, Glasgow BJ, Baylis HI, Shorr N, Goldberg RA (2007) Eyelid mucous membrane grafts: a histologic study of hard palate, nasal turbinate, and buccal mucosal grafts. Ophthal Plast Reconstr Surg 23: 211-216. 
Widera D, Grimm WD, Moebius JM, Mikenberg I, Piechaczek C, Gassmann G, Wolff NA, Thevenod F, Kaltschmidt C, Kaltschmidt B (2007) Highly efficient neural differentiation of human somatic stem cells, isolated by minimally invasive periodontal surgery. Stem Cells Dev 16: $447-460$.

Widera D, Hauser S, Kaltschmidt C, Kaltschmidt B (2012) Origin and regenerative potential of vertebrate mechanoreceptor-associated stem cells. Anat Res Int 2012: 837626.

Widera D, Zander C, Heidbreder M, Kasperek Y, Noll T, Seitz O, Saldamli B, Sudhoff H, Sader R, Kaltschmidt C, Kaltschmidt B (2009) Adult palatum as a novel source of neural crest-related stem cells. Stem Cells 27: 1899-1910.

Xu X, Chen C, Akiyama K, Chai Y, Le AD, Wang Z, Shi S (2013) Gingivae contain neural-crest- and mesodermderived mesenchymal stem cells. J Dent Res 92: 825-832.

Yagita Y, Sakurai T, Tanaka H, Kitagawa K, Colman DR, Shan W (2009) N-cadherin mediates interaction between precursor cells in the subventricular zone and regulates further differentiation. J Neurosci Res 87: 33313342.

Yoshida T, Vivatbutsiri P, Morriss-Kay G, Saga Y, Iseki S (2008) Cell lineage in mammalian craniofacial mesenchyme. Mech Dev 125: 797-808.

Zhang Q, Shi S, Liu Y, Uyanne J, Shi Y, Shi S, Le AD (2009) Mesenchymal stem cells derived from human gingiva are capable of immunomodulatory functions and ameliorate inflammation-related tissue destruction in experimental colitis. J Immunol 183: 7787-7798.

Zhou Y, Snead ML (2008) Derivation of cranial neural crest-like cells from human embryonic stem cells. Biochem Biophys Res Commun 376: 542-547.

\section{Web references}

1. http://blast.ncbi nlm nih.gov/Blast.cgi (01/01/2015)

2. http://mfold.rit.albany.edu/?q=mfold/RNA-FoldingForm (01/01/2015)

\section{Discussion with Reviewers}

Reviewer I: This work describes a method to generate spheres from human gingival cells, which allows enrichment of progenitors with neural crest features and ability to differentiate into neurons. These data open several questions related to the identity of gingival progenitors: Are the spheres containing stem cells able to self-renew and generate secondary spheres? Are gingival cells in the spheres still capable of differentiating into mesenchymal cell types? In other terms, does the in vitro culture system devised by the authors enrich for multipotent neural crestlike stem cells of gingival origin?

Authors: This is a key question and a logical avenue for future research. It will be very interesting to assess whether the neurosphere-enriched populations possess better or different multipotent differentiation potential than their parental cultures. Therefore, this culture system may open new possibilities for isolation of cells for various therapeutic or research approaches. Obtaining tissue biopsies from human gingiva for cell isolation is easy with very little morbidity, making this approach practical and highly feasible. In addition, standard human gingival fibroblast stocks available in many laboratories could be used to enrich these cells for research purposes.

Reviewer I: Neural crest-derived stem cells are easily accessible and ethically unquestioned resources for regenerative medicine. What are the major advantages of NCSCs from the gingiva compared to other readily and minimally-invasive accessible sources of such cells like adipose tissue?

Authors: As the research techniques and understanding to assess the developmental origin of various cells have progressed, several tissues, including dermis and adipose tissue, previously thought to originate from mesoderm, have been shown to contain a subpopulation of cells that have neuroectodermal (neural crest) origin. Subsequent experiments have further shown that these cells, indeed, have differentiation potential beyond the traditional mesenchymal lineages, and can also generate neural cell types. This has opened up novel avenues to isolate and utilise neural crest-derived cells for research and trials for clinical applications. For utility of any therapeutic cell type, an easy, non-invasive and abundant source is an advantage. For this reason, adipose tissue appears a promising source of these cells. Human gingiva is another easily accessible tissue where wound healing after biopsy is fast with very little morbidity. Furthermore, many laboratories have for decades collected and used gingival fibroblasts for various purposes, and these cultures are readily available to study neural crest-like cells. It will be important in the future to compare in further detail the abundance of these cells in various tissues, and cell cultures established from them. Furthermore, it is possible that these cells have distinct properties based on their tissue origin. Such differences have been suggested to arise during migration of the neural crest-derived cells to their final destination, and may also be dependent on the local tissue niche. Therefore, comparing characteristics of neural crest-derived cells from various adult tissue origins will be important for their future utility in research and therapy.

Reviewer III: What is the proof that human cells isolated from adult gingival tissue are neural crest-derived?

Authors: This is an important question. Lineage tracing experiments that are widely used tools in transgenic animals to assess cellular origins cannot be applied in human tissues. Determining NC origin in human cells is complicated by the fact that there is currently no single specific NC marker that would explicitly point to the NC-origin of cultured cells. Therefore, in human tissues and cells we usually have to utilise indirect evidence from various approaches. In the present study, we show that gingival cells express a set of genes that have been previously associated with the NC-phenotype in various contexts in the literature. As further evidence, we also assessed neurosphere generation and neuronallike differentiation potential, both previously described characteristic of NC-cells. However, we appreciate that 
this evidence cannot provide explicit proof that the cells are NC-derived, but suggest that this is a possibility as the cells display many of the NC-like properties.

Reviewer III: To what extent do the authors believe that $\mathrm{NC}$-derived cells from adult tissues are able to behave like embryonic NC cells?

Authors: The NC-derived cells in adult oral tissues can be considered post-migratory $\mathrm{NC}$ cells that may have undergone phenotype changes after they have migrated out of their original niche to their adult tissue location. Therefore, they may have lost some of the characteristics of the embryonic NC cells. However, an intriguing question is whether they may display characteristics of embryonic NC cells when exposed to the embryonic tissue niche. Several studies have shown the importance of the tissue niche to regulate progenitor cell phenotype. An interesting finding from the present study was the molecular composition and organisation of the neurospheres formed by the gingival cells. Neurospheres were composed of distinctly organised and polarised extracellular matrix, reminiscent of embryonic neural crest, which was underlying the highly polarised nestin positive cells. Thus, this mode of culture allowed the adult cells to produce a tissue niche that showed some similarities to the embryonic niche. A very interesting future study would be to test the effect of the embryonic-like $v s$. adult gingiva tissue niche on adult gingiva-derived cell phenotype, and whether embryoniclike ECM can be used to further enhance the NC cell phenotype.

Editor's Note: Scientific Editor in charge of the paper: Martin Stoddart. 